Thiago Guarato Rodrigues Costa

\title{
PREVALÊNCIA DE HIPORREATIVIDADE PLAQUETÁRIA EM PACIENTES COM IAM TRATADOS COM TICAGRELOR
}

\author{
Dissertação apresentada à Faculdade \\ Israelita de Ciências da Saúde Albert \\ Einstein para obtenção do Título de Mestre \\ em Ciências da Saúde.
}


Thiago Guarato Rodrigues Costa

\title{
PREVALÊNCIA DE HIPORREATIVIDADE PLAQUETÁRIA EM PACIENTES COM IAM TRATADOS COM TICAGRELOR
}

\author{
Dissertação apresentada à Faculdade \\ Israelita de Ciências da Saúde Albert \\ Einstein para obtenção do Título de Mestre \\ em Ciências da Saúde. \\ Orientador: Prof. Dr. Antonio Eduardo \\ Pereira Pesaro
}


C837p

Costa, Thiago Guarato Rodrigues

Prevalência de hiporreatividade plaquetária em pacientes com IAM tratados com ticagrelor / Thiago Guarato Rodrigues Costa. -- São Paulo, 2019.

viii, $31 \mathrm{f}$.

Dissertação (Mestrado) - Faculdade Israelita de Ciências da Saúde Albert Einstein. Instituto Israelita de Ensino e Pesquisa Albert Einstein. Programa de Pós-Graduação em Ciências da Saúde.

Título em inglês: Low Platelet reactivity prevalence in patients with acute myocardial infarction treated with ticagrelor.

1. Infarto do miocárdio. 2. Ticagrelor. 3. Hemorragia. 4. Ativação plaquetária.

NLM - WG 310

Elaborada pelo Sistema Einstein Integrado de Bibliotecas 
FACULDADE ISRAELITA DE CIÊNCIAS DA SAÚDE ALBERT EINSTEIN

Coordenador do Curso de Pós-Graduação: Prof. Dr. Luiz Vicente Rizzo 
Thiago Guarato Rodrigues Costa

\section{PREVALÊNCIA DE HIPORREATIVIDADE PLAQUETÁRIA EM PACIENTES COM IAM TRATADOS COM TICAGRELOR}

Presidente da banca: Prof. Dr. Antonio Eduardo Pereira Pesaro

BANCA EXAMINADORA

Membros titulares:

Dr. Amit Nussbacher

Dr. Antonio Carlos Bacelar Nunes Filho

Prof. Dr. Marcel Liberman

Membros suplentes:

Dr. Carlos Augusto Homem de Magalhães Campos

Profa. Dra. Samira Saady Morhy

Aprovada em: 20/12/2019. 


\section{Sumário}

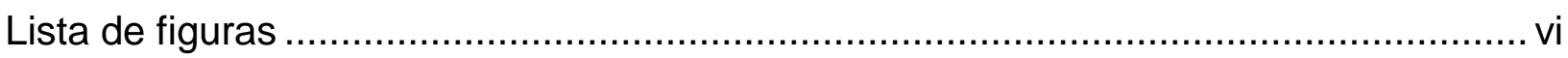

Lista de abreviaturas ...................................................................................... vii

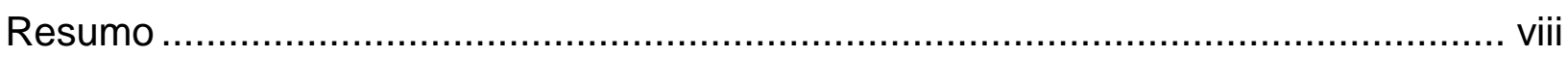

1 INTRODUÇÃO

1.1 Tratamento antiplaquetário das síndromes coronarianas agudas: redução de eventos isquêmicos e risco de sangramento ......................................................

1.2 Monitoramento do tratamento antiplaquetário em pacientes coronariopatas ............5

1.3 Reatividade plaquetária e risco de sangramentos em pacientes tratados com

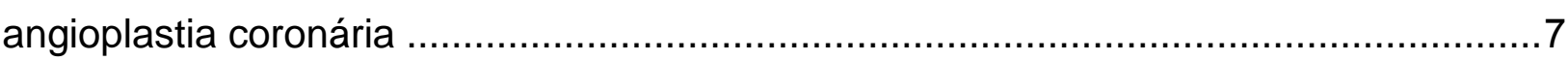

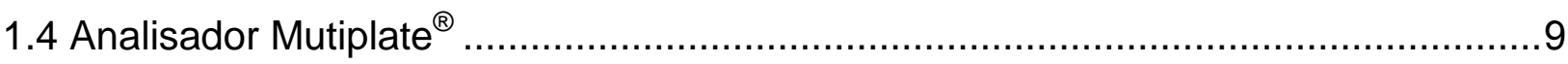

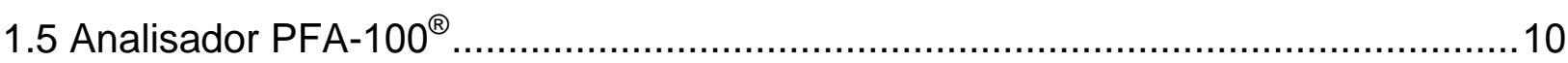

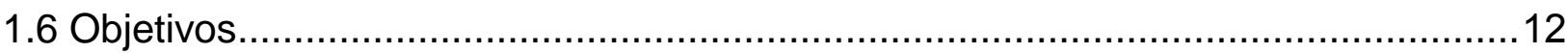

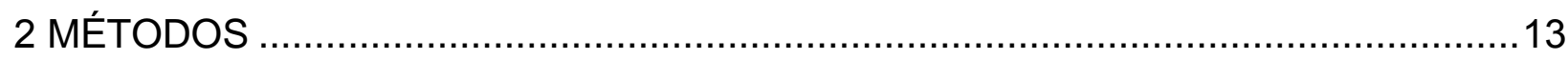

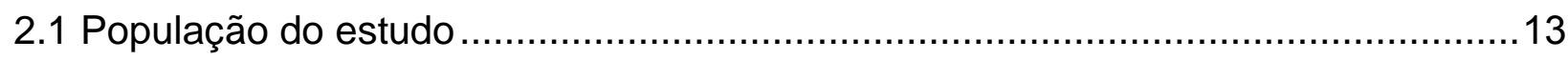

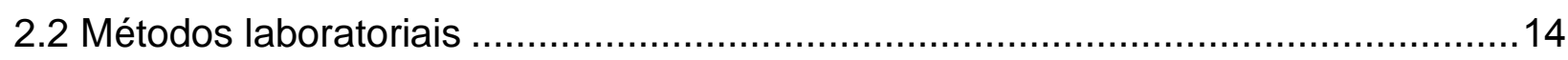

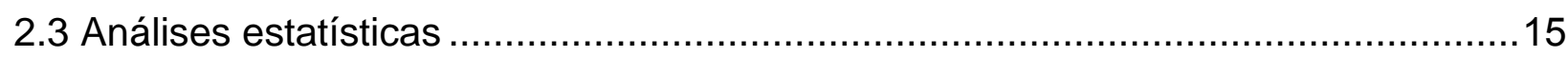

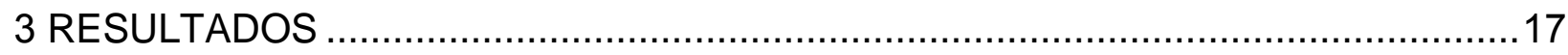

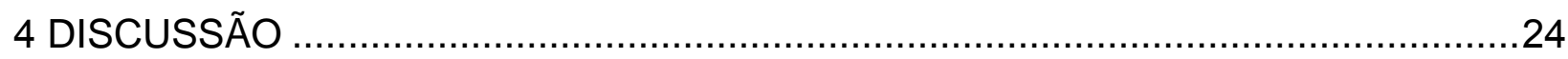

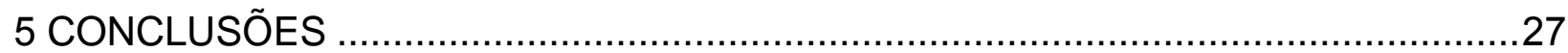

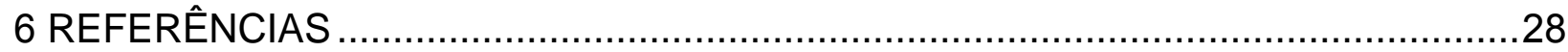

Abstract 


\section{Lista de figuras}

Figura 1. Processo inflamatório arterial na aterosclerose

Figura 2. Ensaio de agregação plaquetária por turbidimetria em plasma rico em plaquetas $(A)$ e seu registro em um teste com plaquetas normais $(B)$ 6

Figura 3. Janela terapêutica e riscos adversos da reatividade plaquetária na inibição dos receptores $\mathrm{P}_{2} \mathrm{Y}_{12}$

Figura 4. Adesão de plaquetas na superfície dos eletrodos da célula de teste

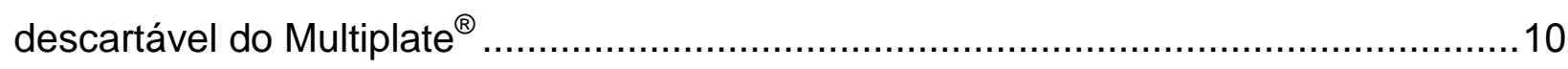

Figura 5. Figura esquemática do sistema PFA $-100^{\circledR}$ 11

Figura 6. Resultado dos testes Multiplate ${ }^{\circledR} A D P$ (expresso em AUC); PFA ${ }^{\circledR} P 2 Y$ e PFA ${ }^{\circledR} \mathrm{Col} / \mathrm{ADP}$ (expresso em segundos) no vale e pico do ticagrelor . 22

Figura 7. Prevalência de hiporreatividade plaquetária por metodologias .23 


\section{Lista de abreviaturas}

AAS Ácido Acetil Salicílico

ADP Adenosina Difostato

AUC Area Under Curve

AVC Acidente Vascular Cerebral

CYP450 Citocromo P450

DLP Dislipidemia

DM Diabetes Mellítus

ESC European Society of Cardiology

HAS Hipertensão Arterial Sistêmica

IAM Infarto Agudo do Miocárdio

POCT Point of Care Test

PRI Platelet Reactivity Index

PRP Plasma Rico em Plaquetas

PRU Platelet Reactivity Units

SBC Sociedade Brasileira de Cardiologia

SCA Síndrome Coronariana Aguda

TFP Teste de Função Plaquetária

VASP Vasodilator Stimulated Phosphoprotein 


\section{Resumo}

Introdução: Em pacientes com síndromes coronarianas agudas o ticagrelor está associado à redução de eventos cardiovasculares, mas também pode acarretar algum incremento no risco de sangramentos quando comparado a clopidogrel. Adicionalmente, a hiporreatividade plaquetária sob tratamento com inibidores do receptor $\mathrm{P}_{2} \mathrm{Y}_{12}$ é um dos fatores associados a maior risco hemorrágico. Objetivo: Mensurar a prevalência de hiporreatividade plaquetária em pacientes com infarto agudo do miocárdio tratados com ticagrelor. Métodos: Pacientes com infarto agudo do miocárdio em uso de ticagrelor ( $n=50,84 \%$ homens, idade $59,3 \pm 12,7$ anos) foram incluídos entre março de 2016 e janeiro de 2018. Amostras de sangue foram coletadas 1 hora antes (vale) e 2 horas após (pico) da dose de manutenção $(90 \mathrm{mg})$ de ticagrelor. A reatividade plaquetária foi mensurada pelos métodos Multiplate ${ }^{\circledR}$ e PFA- $100^{\circledR}$ com os cartuchos Innovance ${ }^{\circledR}$ PFA-P2Y e Col/ADP. Pacientes com valores de reatividade $<19$ AUC para o Multiplate ${ }^{\circledR}$ ou tempo de oclusão $>299$ segundos para o $P F A^{\circledR} P 2 Y$ ou $>116$ segundos para o PFA ${ }^{\circledR} \mathrm{Col} / \mathrm{ADP}$ foram considerados hiporreativos. Uma regressão logística múltipla, ajustada para as variáveis clínicas e laboratoriais, foi realizada para identificar os fatores associados à hiporreatividade plaquetária no pico de ação do ticagrelor. $O$ valor $-p<0,05$ foi considerado estatisticamente significativo. Resultados: $A$ reatividade plaquetária média no pico de ticagrelor foi respectivamente $14 \pm 6$ AUC, $277 \pm 60$ segundos e $166 \pm 100$ segundos, para Multiplate ${ }^{\circledR}, \mathrm{PFA}^{\circledR} \mathrm{P} 2 \mathrm{Y}$ e PFA ${ }^{\circledR} \mathrm{Col} / \mathrm{ADP}$. Para cada método, a comparação das medições entre vale e pico não apresentou diferenças. A prevalência de hiporreatividade plaquetária no pico de ação do fármaco foi semelhante quando aferida pelo Multiplate ${ }^{\circledR}$ e $P F A^{\circledR} P 2 Y$, mas inferior a ambos quando aferida pelo $P F A^{\circledR}$ Col/ADP (respectivamente 74, 86 e 48\%; $\mathrm{p}<0,001$ ). Conclusão: Pacientes com infarto agudo do miocárdio tratados com ticagrelor apresentaram alta prevalência de hiporreatividade plaquetária. A hiporreatividade plaquetária foi mais prevalente quando aferida pelo Multiplate ${ }^{\circledR}$ e $P F A^{\circledR} \mathrm{P} 2 \mathrm{Y}$, em comparação com o $P F A^{\circledR} \mathrm{Col} / \mathrm{ADP}$. A inibição plaquetária foi semelhante no pico e vale de ação do fármaco. Estudos futuros são necessários para avaliar se doses menores de ticagrelor poderiam atenuar a hiporreatividade plaquetária, e possivelmente reduzir o risco hemorrágico de pacientes com infarto agudo do miocárdio.

Descritores: Infarto do miocárdio; Ticagrelor; Hemorragia; Reatividade plaquetária 


\section{INTRODUÇÃO}

As doenças cardiovasculares representam um importante problema de saúde pública no Brasil com altas taxas de incidência e morbimortalidade. Dentre elas, o infarto agudo do miocárdio (IAM) é a principal causa isolada de morte no país apesar dos inúmeros avanços terapêuticos obtidos na última década. ${ }^{(1,2)}$

O IAM é uma síndrome coronariana aguda (SCA) em que ocorre a morte de cardiomiócitos por isquemia prolongada, com elevação de marcadores bioquímicos de necrose miocárdica associado a sinais e sintomas clínicos e/ou positividade de exames complementares. ${ }^{(3,4)} \mathrm{A}$ isquemia ocorre de forma aguda, no entanto, a doença que desencadeia esse bloqueio é desenvolvida de forma lenta e silenciosa ao longo de vários anos, denominada aterosclerose (Figura1). O seu desenvolvimento está relacionado diretamente a idade, presença de distúrbios e doenças crônicas como a dislipidemia (DLP), hipertensão arterial sistêmica (HAS), obesidade, diabetes mellitus (DM) e hábitos como tabagismo e sedentarismo. ${ }^{(5,6)}$

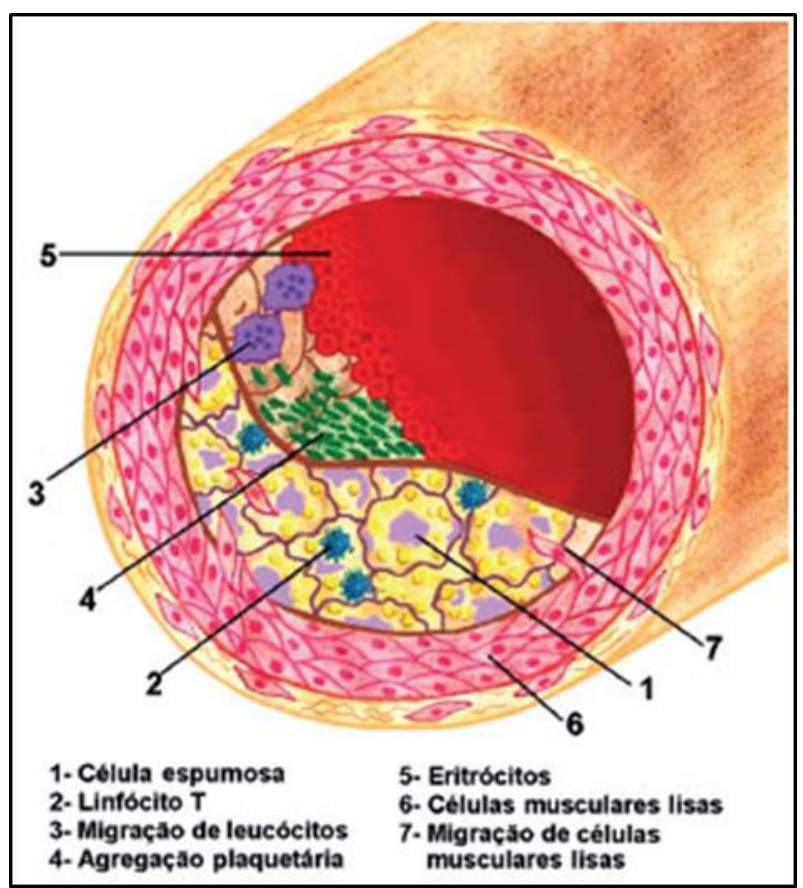

Fonte: Mesquita ET, Demarchi AV, Bitencourt DS, Machado PA, Badran PM, Almeida RG, et al. Continuum cardiovascular 25 anos: evolução de um modelo etiofisiopatológico. Int $\mathrm{J}$ Cardiovasc Sci. 2016;29(1):56-64. Figura 4, Disfunção endotelial na aterosclerose; p. 61.

Figura 1. Processo inflamatório arterial na aterosclerose 
$\mathrm{Na}$ aterosclerose ocorre o acúmulo de lipídeos e células inflamatórias na parede das artérias, reduzindo a luz do vaso de forma progressiva. ${ }^{(7)}$ Durante sua evolução a resposta inflamatória desencadeada pode desestabilizar a placa aterosclerótica, expondo as plaquetas circulantes à substâncias fortemente trombogênicas, que levam a ativação, adesão e agregação plaquetária intrínseca. ${ }^{(5,7)}$ Essa primeira fase de ativação das plaquetas faz com que uma cadeia de reações ocorra levando à geração de um pool de trombina, considerado o agonista plaquetário mais potente, aumentando a ativação e degranulação plaquetária, favorecendo a propagação e estabilização de um trombo ativo, resultando na oclusão arterial. ${ }^{(8,9)}$

Além da trombina, outro agonista extremamente importante na fisiologia da ativação plaquetária é o Adenosina Difosfato (ADP), um dos principais componentes da liberação granular de plaquetas ativadas. O ADP age como agonista de dois principais receptores - o $P 2 Y_{1}$ e o $P 2 Y_{12}$. A ativação do $P 2 Y_{1}$ dá início à agregação plaquetária e a estimulação do $P 2 Y_{12}$ amplifica e estabiliza a resposta de agregação. Devido ao seu importante papel na agregação plaquetária, o receptor $\mathrm{P}_{2} \mathrm{Y}_{12}$ tornou-se um dos principais alvos da terapia antiplaquetária. ${ }^{(9)}$

\subsection{Tratamento antiplaquetário das síndromes coronarianas agudas: redução de eventos isquêmicos e risco de sangramento}

O tratamento antiplaquetário está associado à redução do risco de eventos trombóticos pós-IAM, no entanto, esta redução está atrelada ao aumento do risco hemorrágico. As drogas antiplaquetárias estão entre os medicamentos mais utilizados no mundo. $O$ ácido acetil salićlico (AAS) é considerado a principal delas devido a sua segurança, custo-efetividade e evidências científicas. O duplo tratamento antiplaquetário de classe I (associação do AAS a um agente inibidor do receptor P2Y ${ }_{12}$ ) é uma eficiente terapia comprovada e utilizada em pacientes com SCA. ${ }^{(10,11)}$

Existem 2 classes de drogas antagonistas do receptor $\mathrm{P}_{2} \mathrm{Y}_{12}$, as tienopiridinas, inibidores indiretos e irreversíveis e, as não tienopiridinas, inibidores diretos e reversíveis da ativação e agregação plaquetária induzida por ADP. O clopidogrel e o prasugrel são membros da classe das tienopiridinas e sua ação inibe seletivamente os receptores plaquetários de ADP irreversivelmente. Ambos são 
administrados como pró-droga e o metabólito ativo é formado através da oxidação regulada pelas enzimas do citocromo P450 (CYP450).

O clopidogrel inibe a agregação plaquetária a partir de 2 horas após administração e cerca de $50 \%$ da sua excreção é realizada via renal. Possui eficácia comprovada em diversos ensaios clínicos com redução nas taxas de eventos isquêmicos como óbito, IAM e acidente vascular cerebral (AVC) e taxas não significativas de sangramento grave. No CURE, estudo randomizado, duplo-cego, placebo-controlado, que comparou o clopidogrel associado à aspirina ao placebo em pacientes com SCA, os benefícios de redução de eventos isquêmicos em pacientes submetidos à intervenção coronariana foram evidentes em 12 meses de acompanhamento (9,6\% versus $11,4 \%$; $\mathrm{HR}=0,80$; IC $95 \%$ 0,72-0,90; $\mathrm{p}<0,001)$, com taxa significativa de sangramento major $(3,7 \%$ versus $2,7 \%$; $\mathrm{HR}=1,38$; IC $95 \% 1,13$ $1,67 ; p=0,001) .{ }^{(12)}$

O Prasugrel é um tienopiridínico de ação rápida, convertido em metabólito ativo através do metabolismo via CYP450 e pico de concentração plasmática ocorrendo em aproximadamente 30 minutos. De acordo com TRITON-TIMI 38, estudo fase 3, multicêntrico, randomizado, com 13.608 pacientes, o prasugrel demonstrou eficácia superior ao clopidogrel na redução do desfecho primário (composto por óbito, IAM e AVC) (9,9\% versus 12,1\%; HR=0,81; IC 95\% 0,73$0,90 ; p<0,001)$ e trombose de stents $(1,1 \%$ versus $2,4 \%$; HR=0,48; IC $95 \% 0,36$ $0,64 ; p<0,001)$ em 15 meses de seguimento com taxas de sangramento significativas entre os grupos $\left(2,4 \%\right.$ versus $1,8 \% ; H R=1,32 ;$ IC $95 \% 1,03-1,68 ; p=0,03 .{ }^{(13)}$

Apesar da eficácia comprovada do clopidogrel no CURE, seu efeito farmacodinâmico demonstrou ser amplamente variável, com presença de alta reatividade plaquetária em mais de $30 \%$ dos pacientes em uso da medicação na dose padrão. ${ }^{(14)}$ Para o tratamento com prasugrel, quando em pacientes com maior risco hemorrágico (idade superior à 75 anos e/ou peso inferior à $60 \mathrm{~kg}$ ), ataque isquêmico transitório e AVC prévio, deve ser evitado ou introduzido com restrição. ${ }^{(15)}$

Ao contrário das anteriores, o ticagrelor é uma droga ativa pertencente ao grupo das não tienopiridinas, age diretamente sobre o receptor $\mathrm{P} \mathrm{Y}_{12}$ da superfície plaquetária de forma reversível e induz uma inibição plaquetária mais potente a partir de 30 minutos após a sua administração. A eficácia e segurança dessa droga em portadores de SCA foram avaliadas no estudo PLATO (Platelet Inhibition and Patient Outcomes) com significativa redução de óbitos por causas 
cardiovasculares, IAM e AVC comparado ao clopidogrel (9,8\% versus $11,7 \%$; $H R=0,84$; IC 95\% 0,77-0,92; $p<0,001)$ em 12 meses de seguimento. ${ }^{(16)}$ Não houve diferença significativa de sangramento entre os grupos ticagrelor e clopidogrel $(11,6 \%$ versus 11,2\%; HR=1,04; IC 95\% 0,95-1,13 p=0,43), mas o uso de ticagrelor foi associado com maior taxa de sangramento não relacionada à revascularização miocárdica aberta (4,5\% versus 3,8\%; HR=1,19; IC 95\% 1,02-1,38; $\mathrm{p}=0,03) .{ }^{(16,17)}$

Recomenda-se como posologia uma sobrecarga de $180 \mathrm{mg}$ como dose de ataque, seguida da dose de manutenção de $90 \mathrm{mg}$ duas vezes ao dia. Apesar do alto risco de eventos isquêmicos recorrentes e complicações hemorrágicas relacionadas ao tratamento antitrombótico em idosos, o ajuste de dose para o ticagrelor não é necessário nesse subgrupo e em pacientes com insuficiência renal. Um estudo derivado do PLATO com pacientes idosos ( $\geq 75$ anos) mostrou que o benefício clínico global e a segurança do ticagrelor comparado ao clopidogrel na SCA foi observado independente da idade. O ticagrelor foi mais efetivo que o clopidogrel na redução de eventos isquêmicos (17,2\% versus $18,3 \%$; $H R=0,89 ;$ IC 95\% 0,74-1,08; $p=0,56)$, com redução absoluta da mortalidade global de $2,6 \%$ nos pacientes $\geq 75$ anos e 1,2\% nos pacientes $<75$ anos. Também não houve diferença estatística quanto às taxas de sangramento major entre os subgrupos etários ( $<75$ anos e $\geq 75$ anos) para ambas as drogas. Com isso, o ticagrelor se tornou uma opção de primeira linha em associação ao AAS no duplo tratamento antiplaquetário em SCA tratadas. ${ }^{(18)}$

Baseado em estudos anteriores, Bonaca et al. realizaram o estudo PEGASUS-TIMI 54, multicêntrico randomizado, paralelo, duplo-cego e placebocontrolado comparando 2 diferentes doses de ticagrelor versus placebo em portadores de doença coronária de alto risco. No entanto, diferentemente do estudo anterior, este ensaio selecionou pacientes em fase crônica, com IAM prévio entre 1 e 3 anos em uso de AAS. Ao todo, 21.162 pacientes foram randomizados para receber ticagrelor $90 \mathrm{mg}$ $2 x /$ dia $(n=7.050)$ ou ticagrelor $60 \mathrm{mg} 2 x /$ dia $(n=7.045)$ ou placebo $(n=7.067)$. Após um seguimento médio de 33 meses, as duas doses de ticagrelor reduziram significativamente o desfecho primário composto por óbito, IAM ou AVC em comparação com o placebo, e não diferiram significativamente entre si. Por outro lado, as taxas de sangramento e dispneia foram numericamente menores com a dose de $60 \mathrm{mg}$ de ticagrelor do que com a dose de $90 \mathrm{mg}$ (sangramentos TIMI major com o uso de ticagrelor 90mg 2x/dia (2,60\%; HR versus placebo 2,69; $p<0,001)$ e com o uso de ticagrelor $60 \mathrm{mg} 2 \mathrm{x} / \mathrm{dia}$ (2,30\%; HR versus placebo 2,32; $\mathrm{p}<0,001)$, resultando em uma 
menor taxa de descontinuação do medicamento do estudo e um melhor perfil de segurança com a dose de $60 \mathrm{mg} .{ }^{(19,20)}$ Apesar dos potenciais benefícios de segurança da dose de manutenção de $60 \mathrm{mg}$ demonstrados no estudo PEGASUS-TIMI 54, essa dose nunca foi testada em pacientes portadores de SCA.

\subsection{Monitoramento do tratamento antiplaquetário em pacientes coronariopatas}

Existe uma forte associação entre eventos hemorrágicos e trombótico cardiovasculares com a reatividade plaquetária, principalmente em pacientes submetidos à intervenção coronariana, e por isso o monitoramento da terapia antiplaquetária foi extensamente investigado em estudos clínicos. ${ }^{(14)}$ Atualmente, os dispositivos utilizados na avaliação da função plaquetária são baseados em diferentes metodologias e isso requer experiência na execução e interpretação dos resultados. As plaquetas são facilmente ativadas e diversas variáveis pré-analíticas podem afetar suas funções, por isso, uma série de boas práticas devem ser seguidas desde a coleta até o processamento das amostras para que os resultados sejam fidedignos à clínica dos pacientes. $^{(20)}$

A agregometria por turbidimetria (Figura 2) em plasma rico em plaquetas (PRP) ainda é considerada o teste padrão-ouro, no entanto, devido a falta de padronização, as amostras podem sofrer interferências em diversas fases do processamento. A técnica pode ser afetada pela variação na velocidade de centrifugação e contaminação com eritrócitos durante a fase de preparação do PRP, parâmetros de agitação, diferenças de concentração dos agonistas durante a preparação ou pipetagem manual e, elevado tempo de processamento na fase analítica, além disso, a metodologia requer grandes volumes de amostra e não possui controles comerciais que avaliem a precisão dos testes e garantem a exatidão dos resultados. ${ }^{(21,22)}$ 


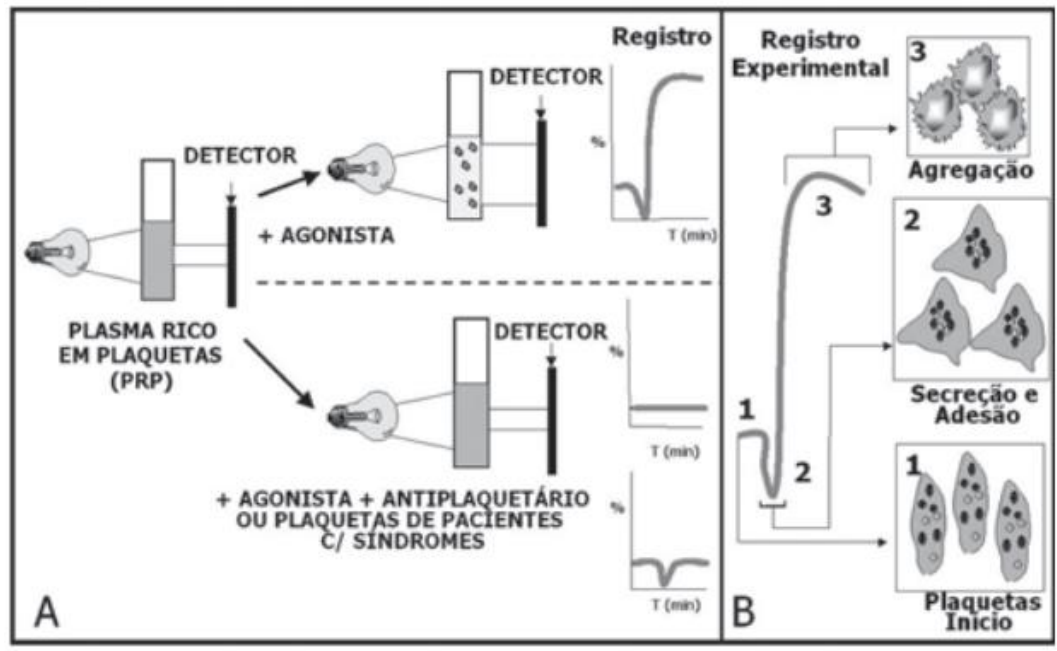

Fonte: Castro HC, Ferreira BL, Nagashima T, Schueler A, Rueff C, Camisasca D, et al. Plaquetas: ainda um alvo terapêutico. J Bras Patol Med Lab. 2006;42(5):321-32. Figura 3, Ensaios de agregação plaquetária no agregômetro (A) e seu registro experimental (B); p. 325.

Figura 2. Ensaio de agregação plaquetária por turbidimetria em plasma rico em plaquetas $(A)$ e seu registro em um teste com plaquetas normais (B)

Os ensaios que utilizam amostras de sangue total conferem algumas vantagens no estudo da função plaquetária por evitar a sua ativação devido a ausência de centrifugação, reproduzir melhor as condições in vivo por incluir no processo de agregação a interação com os glóbulos vermelhos e brancos, permitir a avaliação global ou de fases específicas como ativação, adesão e secreção plaquetária em diversos testes com diferentes sensibilidades, seja na detecção de anomalias plaquetárias ou no monitoramento antiplaquetário. ${ }^{(20,23)}$

A avaliação da eficácia do tratamento antiplaquetário ajustado com base em testes de função plaquetária (TFP) foi realizada em grandes ensaios clínicos envolvendo milhares de pacientes. Em 2010, o estudo prospectivo POPULAR (Do Platelet Function Assays Predict Clinical Outcomes in Clopidogrel Pretreated Patients Undergoing Elective $\mathrm{PCl}$ ) recrutou consecutivamente, em centro único, 1069 pacientes submetidos a implante de stent coronário e que haviam recebido a dose padrão de clopidogrel associado à aspirina, para avaliação da reatividade plaquetária em 5 sistemas diferentes (entre eles: agregometria ótica, VerifyNow e $P F A-100^{\circledR}$ ), afim de avaliar a capacidade destes em predizer desfechos clínicos. Após 12 meses de acompanhamento, a ocorrência de eventos isquêmicos foi maior em pacientes que apresentaram alta reatividade plaquetária, e apenas 3 metodologias foram significativamente associadas aos desfechos, porém a precisão prognóstica dos testes 
foi moderada e nenhum deles conseguiu fornecer informações sobre o risco de sangramento dos pacientes incluídos. ${ }^{(24)}$

Seguindo a ótica desse estudo, em 2011, o GRAVITAS (Gauging Responsiveness With a VerifyNow Assay-Impact on Thrombosis and Safety) recrutou 2214 pacientes submetidos à intervenção coronariana com alta reatividade plaquetária ao tratamento com clopidogrel, medidos pelo VerifyNow. Os indivíduos foram randomizados à continuidade do tratamento com clopidogrel na dose padrão e em altas doses, afim de avaliar o efeito do ajuste de dose baseado nos resultados de um teste de função plaquetária, porém, os resultados não reduziram as taxas de desfechos isquêmicos e trombose de stent após 6 meses de acompanhamento (2,3\% versus 2,3\%; HR=1,01; 95\% IC 0,58-1,76; $\mathrm{p}=0,97$ ). ${ }^{(25)} \mathrm{Em} 2012$, o ARCTIC (Assessment by a Double Randomization of a Conventional Antiplatelet Strategy versus a MonitoringGuided Strategy for Drug-Eluting Stent Implantation and of Treatment Interruption Versus Continuation One Year After Stenting) distribuiu aleatoriamente 2440 pacientes submetidos a implante eletivo de stent coronário, em 2 grupos: os submetidos à monitoramento através do VerifyNow e ajuste de dose para o tratamento antiplaquetário, se necessário, e aqueles sem monitoramento e sem ajuste de dose. Os pacientes que apresentaram alta reatividade plaquetária ao clopidogrel receberam uma dose adicional de antitrombóticos e ainda assim, a ocorrência de desfecho primário não diferiu entre os 2 grupos $(34,6 \%$ versus $31,1 \%$; HR=1,13; $95 \%$ IC 0,98 - 1.29; $\mathrm{p}=0,10){ }^{(26)}$

A despeito da elevada reatividade plaquetária sob tratamento com clopidogrel se associar à ocorrência de eventos trombóticos, estes estudos demonstraram que os TFPs permitem apenas uma avaliação plaquetária global e podem ser utilizados para estratificar o risco de trombose de stent durante o tratamento com antiplaquetários. $O$ ajuste de doses e estratégias baseado no resultado desses testes não adicionou benefícios à terapia convencional. ${ }^{(27)}$

\subsection{Reatividade plaquetária e risco de sangramentos em pacientes tratados com angioplastia coronária}

O poder preditivo de sangramentos dos testes plaquetários em pacientes com angioplastia coronária apresentou resultados controversos em estudos 
prévios, fato possivelmente associado à variabilidade de métodos laboratoriais e das populações estudadas (pacientes com SCA ou pacientes eletivos com doença estável).

O estudo POPULAR utilizou diversos métodos de mensuração da reatividade plaquetária e não demonstrou qualquer valor preditivo em relação a sangramentos. ${ }^{(24)}$ Por outro lado, um estudo unicêntrico que incluiu 2533 pacientes submetidos à angioplastia coronária demonstrou que a reatividade plaquetária muito baixa ao clopidogrel estava associada a um risco três vezes maior de eventos hemorrágicos intra-hospitalares. ${ }^{(10)}$ Mais recentemente, os resultados de 1 ano do registro multicêntrico ADAPT-DES mostraram em 8500 pacientes que, a reatividade plaquetária mais baixa no tratamento com clopidogrel, mensurada pelo VerifyNow após angioplastia coronária [Platelet Reactivity Units (PRU) inferior a 208], foi associada a maior risco de sangramento. ${ }^{(28)}$ Nesse sentido, Gurbel et al. levantaram a hipótese inicial da existência de uma janela terapêutica para a reatividade plaquetária, onde os resultados inferiores ao valor de corte aumentam o risco de hemorragia e resultados superiores, elevam as chances de trombose. ${ }^{(29)}$

Uma declaração do grupo de especialistas em trombose da European Society of Cardiology (ESC) sobre o papel dos testes de função plaquetária em pacientes submetidos à intervenção coronariana foi divulgada em 2014 e atualizada em 2018, visando estabelecer valores de corte ideais para risco trombótico e hemorrágico (Figura 3). Dentre os ensaios avaliados estão o Vasodilator Stimulated Phosphoprotein (VASP), metodologia para a avaliação da inibição do receptor de ADP por citometria de fluxo com janela terapêutica para reatividade plaquetária sugerida entre 16 e 50\% PRI (Platelet Reactivity Index). O VerifyNow, equipamento automatizado baseado na detecção turbidimétrica da agregação plaquetária no sangue total, possui o intervalo entre 85 e 208 PRU como range de menor risco para sangramento e eventos isquêmicos, e o Multiplate ${ }^{\circledR}$, equipamento semiautomatizado que simula a ativação e agregação de plaquetas em sangue total através da metodologia de múltiplos eletrodos, com range terapêutico sugerido entre 19 e 46 AUC (Area Under Curve). ${ }^{(14,27)}$ Apesar dos valores sugeridos para janela terapêutica, a avaliação da reatividade plaquetária em pacientes submetidos à intervenção coronariana não deve ser utilizada como parâmetro para individualização do tratamento antiplaquetário, apenas na estratificação de risco de trombose de stent e de sangramento em pacientes tratados com inibidores do receptor $\mathrm{P}_{2} \mathrm{Y}_{12 .}{ }^{(27)}$ 
Os estudos mencionados avaliaram pacientes sob tratamento com clopidogrel e, até o momento, não há esse tipo de evidência em pacientes sob tratamento de ticagrelor. Entretanto, considerando a maior potência antiplaquetária do ticagrelor, podemos supor que níveis muito baixos de reatividade plaquetária nesse cenário terapêutico também tenham impacto no risco de sangramentos.

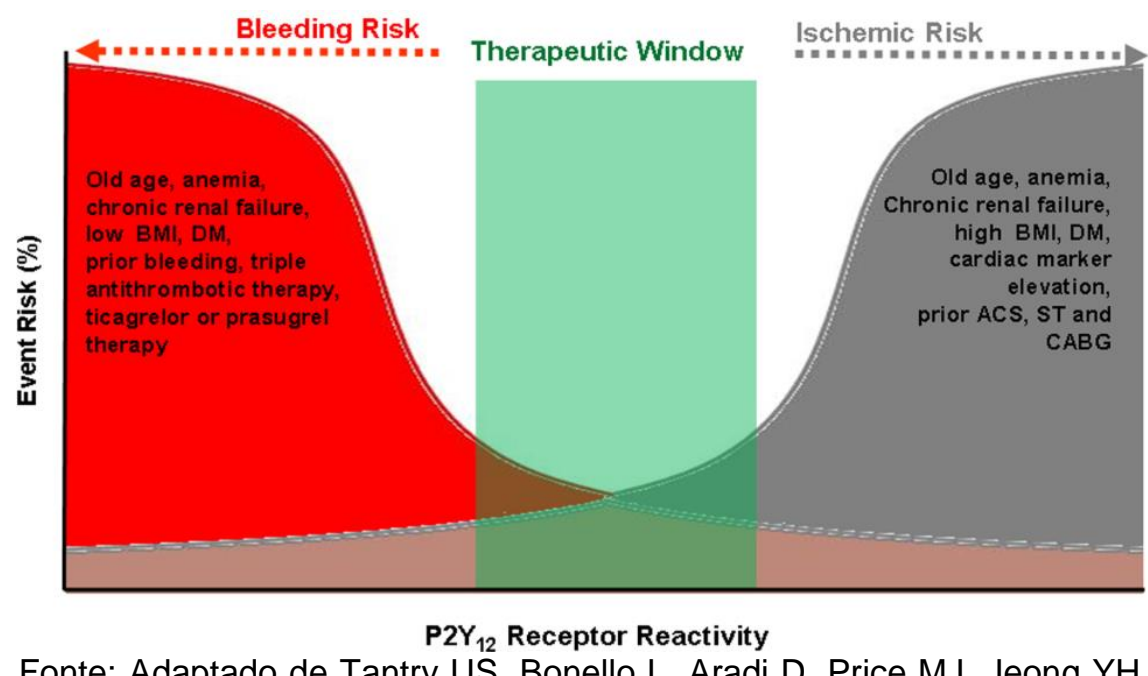

Fonte: Adaptado de Tantry US, Bonello L, Aradi D, Price MJ, Jeong YH Angiolillo DJ, et al. Consensus and update on the definition of ontreatment platelet reactivity to adenosine diphosphate associated with ischemia and bleeding. J Am Coll Cardiol. 2013;62(24):2261-73. Figure 1, Evidence for $\mathrm{P}_{2} \mathrm{Y}_{12}$ receptor reactivity associated with post-PCl ischemic and bleeding events; p. 2267..$^{(15)}$

Figura 3. Janela terapêutica e riscos adversos da reatividade plaquetária na inibição dos receptores $\mathrm{P}_{2} \mathrm{Y}_{12}$

\subsection{Analisador Mutiplate ${ }^{\circledR}$}

O Multiplate $^{\circledR}$ é um equipamento automatizado para avaliação da função plaquetária in vitro por impedância. Este equipamento utiliza uma tecnologia denominada MEA (Multiple Electrode Assay) em que cada célula de teste possui eletrodos independentes duplicados, permitindo a detecção da reatividade plaquetária em amostras de sangue total. Sendo assim, as plaquetas se ativam em um ambiente muito próximo do real, refletido todas as interações celulares que podem influenciar na função plaquetária, apresentando boa correlação comparada aos resultados da metodologia padrão-ouro. Na célula de teste do Multiplate ${ }^{\circledR}$ (Figura 4 ) as plaquetas ativadas se agregam e se aderem aos fios sensores elevando a impedância elétrica 
que, por sua vez, é registrada em forma de curva, e o resultado expresso através do cálculo da área sob a curva AUC. ${ }^{(30,31)}$

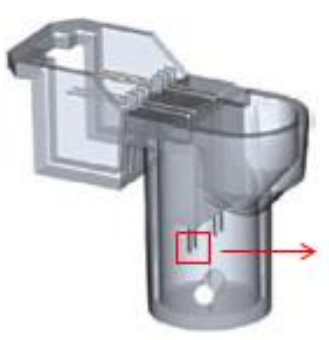

A) Célula de teste descartável

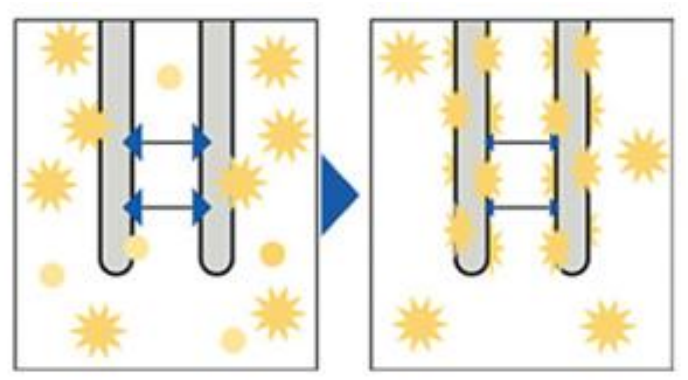

B) Eletrodos e plaquetas em agregação

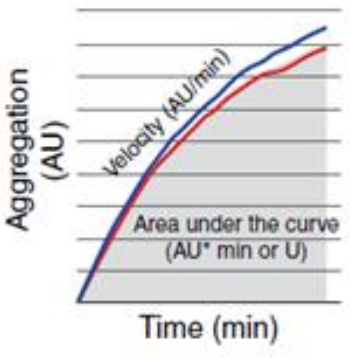

C) Curva de resultado da agregação plaquetária

Fonte: Adaptado de Orban M, Sibbing D. Multiplate analyzer. In: Waksman R, Gurbel PA, Gaglia MA Jr, editors. Antiplatelet therapy in cardiovascular disease. Chichester: Wiley Blackwell; 2014. p. 82-91. ${ }^{(30)}$

Figura 4. Adesão de plaquetas na superfície dos eletrodos da célula de teste descartável do Multiplate ${ }^{\circledR}$

Alguns estudos correlacionaram eventos cardiovasculares e função plaquetária medida pelo Multiplate $^{\circledR}$, no entanto, a maioria deles foi realizada em pacientes sob o uso de clopidogrel, onde a hiperreatividade plaquetária é mais comum devido à existência de baixos respondedores à droga. As evidências entre a hiporreatividade plaquetária e eventos hemorrágicos em pacientes sob o uso de inibidores dos receptores $\mathrm{P}_{2} \mathrm{Y}_{12}$ pós-intervenção coronariana ainda não são tão evidentes. $^{(27,30,32)}$

\subsection{Analisador PFA-100 ${ }^{\circledR}$}

O sistema PFA-100 ${ }^{\circledR}$ é de fácil manuseio, considerado um teste point-of-care (POCT - Point-of-Care Test), possui uma excelente sensibilidade a distúrbios plaquetários hereditários ou adquiridos e drogas antiplaquetárias e, por ser um sistema fechado, apresenta confiabilidade dos resultados podendo ser decisivo na tomada de decisões clínicas comparado a outras metodologias. Foi extensamente estudado na primeira década dos anos 2000 devido a sua inovadora tecnologia que mimetiza in vitro, o processo de formação do trombo in vivo, através do estímulo plaquetário por agonistas fisiológicos contido em um cartucho de teste e somado à alta força de cisalhamento (shear-stress) em amostras de sangue total. Os cartuchos de 
testes do PFA-100 ${ }^{\circledR}$ possuem em seu interior um sistema capilar que, ao ser submetido a condições controladas, simulando o fluxo sanguíneo de um capilar humano, faz com que a amostra passe por um orifício contido em uma membrana revestida com agonistas fisiológicos da ativação plaquetária, simulando uma lesão vascular (Figura 5). O tempo, expresso em segundos, desde o início do teste até a oclusão do orifício pelo tampão plaquetário formado é inversamente proporcional à função plaquetária da amostra. ${ }^{(20,33,34)}$

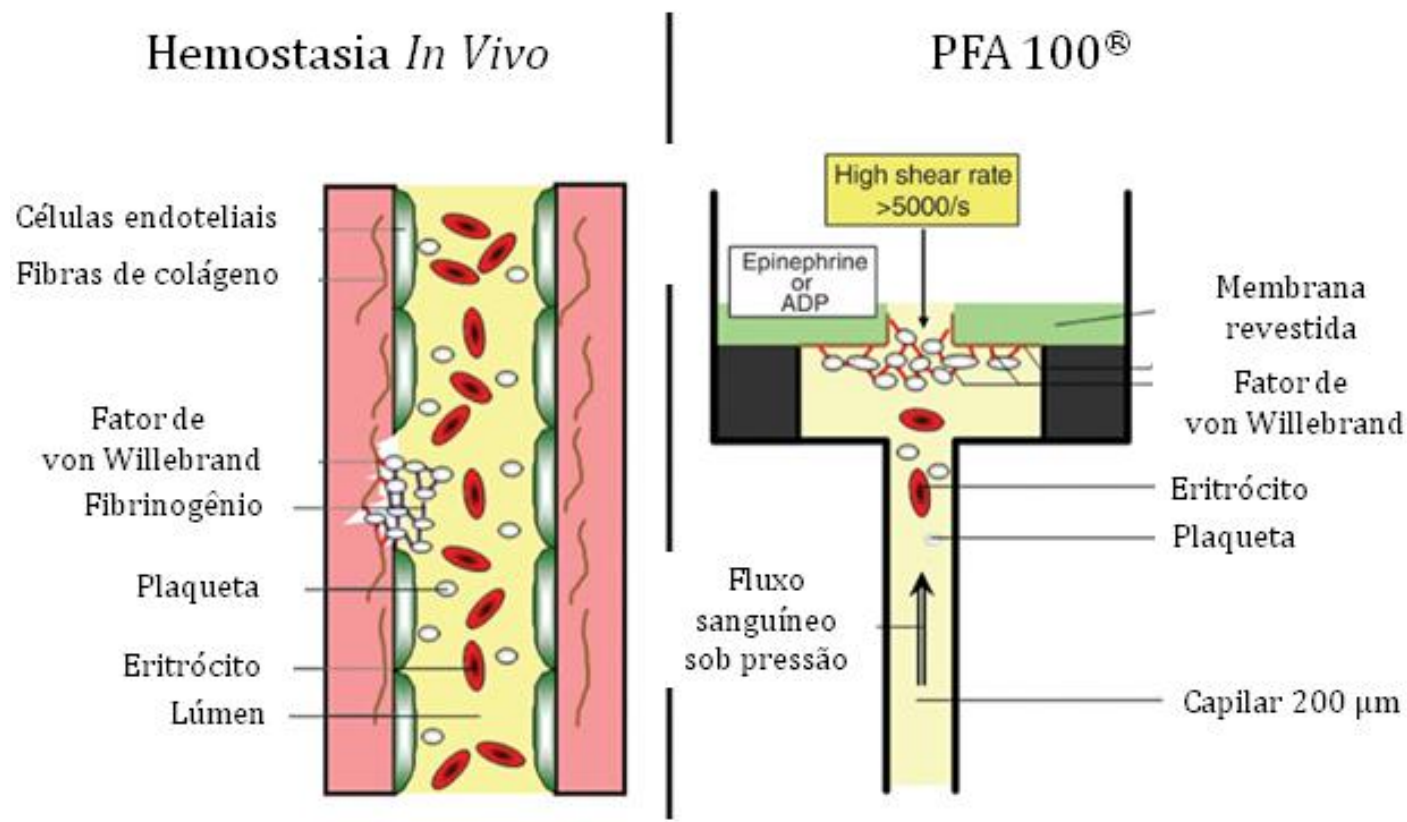

Fonte: Breet NJ, tem Berg JM. Shear stress-based platelet function tests. In: Waksman R, Gurbel PA, Gaglia MA Jr, editors. Antiplatelet therapy in cardiovascular disease. Chichester: Wiley Blackwell; 2014. p. 92-101.

Figura 5. Figura esquemática do sistema PFA-100 ${ }^{\circledR}$

Os primeiros estudos mostraram a utilidade do PFA $-100^{\circledR}$ como uma ferramenta de triagem na detecção de disfunções plaquetárias intrínsecas e doença de von Willebrand (DvW), mas as evidências para o monitoramento antiplaquetário ainda são escassas. No entanto, as atenções se voltaram novamente para o analisador com o desenvolvimento do novo cartucho Innovance ${ }^{\circledR}$ PFA-P2Y, apontado como teste exclusivo para o monitoramento do tratamento antiplaquetário. ${ }^{(33,35-37)}$ Dentre os cartuchos disponíveis, o Col/ADP possui a membrana revestida com colágeno e ADP, realiza o estímulo através de ADP (canal plaquetário alvo deste estudo) e é menos influenciado pelo uso de aspirina, utilizada no tratamento duplo antiplaquetário. O segundo, o novo cartucho Innovance ${ }^{\circledR}$ PFA-P2Y possui a membrana revestida com 
ADP, Prostaglandina E1 e Cálcio, e mede especificamente o efeito dos inibidores dos receptores $\mathrm{P}_{2} \mathrm{Y}_{12}$ na função plaquetária.

Em resumo, os novos inibidores do receptor $\mathrm{P}_{2} \mathrm{Y}_{12}$ (ticagrelor $\mathrm{e}$ prasugrel) apresentam maior poder antiplaquetário e redução do risco trombótico em pacientes com SCA comparados a clopidogrel, com consequente elevação do risco de sangramentos. Evidências prévias demonstraram que em pacientes tratados com clopidogrel e angioplastia coronária, o subgrupo com níveis baixos de reatividade plaquetária apresentaram maior risco de sangramento. O risco de sangramento seria potencialmente ainda agravado naqueles com níveis muito baixos de reatividade plaquetária (i.e. Multiplate ${ }^{\circledR}<19$ AUC), sendo que especialistas sugerem a presença de uma janela terapêutica ideal de inibição plaquetária intermediária (i.e. Multiplate ${ }^{\circledR} 19$ 46 AUC). Em pacientes na fase crônica pós-SCA, uma dose menor de ticagrelor (60mg) é possivelmente mais segura em relação a sangramentos do que a dose de 90mg, com igual benefício antitrombótico, sugerindo que a dose de 90mg possa estar além do necessário para o melhor risco/benefício terapêutico. Nossa hipótese consistiu em que a presença de inibição plaquetária excessiva nesse contexto, poderia ajudar a explicar o aumento de sangramentos dessa estratégia terapêutica.

\subsection{Objetivos}

1. Mensurar a prevalência de hiporreatividade plaquetária ao ticagrelor em pacientes com infarto agudo do miocárdio tratados com angioplastia no vale e pico da droga;

2. Comparar a mensuração da prevalência de hiporreatividade plaquetária entre as metodologias utilizadas pelo Multiplate ${ }^{\circledR}$ e PFA- $100^{\circledR}$;

3. Avaliar características clínicas e laboratoriais associados à hiporreatividade plaquetária ao ticagrelor. 


\section{MÉTODOS}

\subsection{População do estudo}

O estudo foi aprovado pelo comitê de ética local (Sistema Gerenciador de Projeto de Pesquisa (SGPP), Hospital Israelita Albert Einstein, São Paulo, SP, Brasil) de acordo com a declaração de Helsinki e está cadastrado na plataforma Brasil sob número 50157015.6.0000.0071. Foram incluídos consecutivamente entre março de 2016 e agosto de 2018, 50 indivíduos neste estudo prospectivo observacional realizado em um hospital de alta complexidade da cidade de São Paulo, com rastreamento diário de pacientes. O número total de participantes foi baseado em estudo plaquetário prévio, derivado do estudo PLATO, em que 69 pacientes foram incluídos para avaliação plaquetária no pico e vale do Ticagrelor. No entanto, frente à uniformidade dos resultados, dificuldade de aceite dos indivíduos elegíveis devido ao procedimento de coleta exclusivo para este estudo e ao tempo limitado para análises dos dados, encerramos a fase de inclusão com 50 pacientes. Ao todo foram entrevistados 59 pacientes, deste total, 6 se negaram a coletar material para a realização dos testes plaquetários devido ao incômodo da punção e outros 3 tiveram alta antes da realização da primeira coleta. Os elegíveis deveriam ter o diagnóstico de IAM em unidade de Pronto Atendimento até 6 horas após início dos sintomas. O IAM foi definido de acordo com os seguintes critérios de diretrizes internacionais: elevação de marcadores séricos de necrose miocárdica (preferencialmente troponina e/ou CK-MB) associada a pelo menos uma das características: sintomas isquêmicos, ou desenvolvimento de ondas $Q$ patológicas no eletrocardiograma (ECG), ou alterações no ECG indicativas de isquemia (elevação ou depressão do segmento ST), ou evidência por imagem de perda de área viável do miocárdio, ou intervenção na artéria coronária (por exemplo, angioplastia coronariana). ${ }^{(38)}$ Após o diagnóstico, o paciente recebeu dose de ataque de ticagrelor (180mg) associado à AAS e realizaram angiografia coronária (a realização de angioplastia primária não era obrigatória). A escolha do inibidor do receptor P2Y 12 , assim como todas as estratégias terapêuticas, foi a critério da equipe médica do paciente, sem qualquer relação com o presente estudo. Os critérios de exclusão para este estudo foram: uso prévio de anticoagulantes orais, sangramento ativo, distúrbio 
hematológico prévio, uso de agentes trombolíticos, infecção ativa, choque cardiogênico, insuficiência renal dialítica, uso de antiplaquetários inibidores do receptor $\mathrm{P}_{2 Y_{12}}$ que não ticagrelor e/ou uso de inibidores da GPIIbllIA.

\subsection{Métodos laboratoriais}

As coletas de sangue foram realizadas por punção venosa 1 hora antes (vale) e 2 horas após (pico) a dose de manutenção matutina da droga (90mg) com objetivo de testar a reatividade plaquetária em 2 momentos: durante a maior e menor biodisponibilidade da droga, uma vez que a inibição plaquetária pelo ticagrelor ocorre pela ligação direta do seu metabolito ativo aos receptores plaquetários. As amostras de sangue foram encaminhadas imediatamente ao laboratório clínico e processadas em até 2 horas após a coleta, respeitando os tempos de estabilidade plaquetária em sangue total. ${ }^{(39)} \mathrm{O}$ resultado obtido nos testes não foi apresentado para as equipes assistenciais, ficando disponível apenas para a equipe investigadora. As coletas foram realizadas em duas punções, realizadas preferencialmente em membros diferentes, a fim de eliminar qualquer interferente na atividade plaquetária relacionado à punção anterior ou inserção de cateter. Foram coletados tubos com anticoagulante Hirudina para realização dos testes de agregabilidade plaquetária com o equipamento Multiplate ${ }^{\circledR}$ (Roche, Alemanha) e também em tubos de citrato 3,2\% para realização dos testes com o equipamento PFA $-100^{\circledR}$ (Siemens, Alemanha). Os pacientes do estudo foram acompanhados apenas durante o tempo em que permaneceram internados e as avaliações laboratoriais metabólicas e hematológicas foram obtidas através de revisão de prontuário. Todos os incluídos assinaram o termo de consentimento livre e esclarecido.

Os indivíduos participantes realizaram testes de agregação plaquetária induzida por ADP no analisador Multiplate ${ }^{\circledR}$ e no sistema PFA-100 ${ }^{\circledR}$ utilizando o cartucho Innovance ${ }^{\circledR}$ P2Y e Col/ADP. Apesar dos principais estudos plaquetários com Ticagrelor terem sido realizados com analisador VerifyNow, essa metodologia não era utilizada em nosso serviço de medicina diagnóstica. A escolha dos testes realizados nesse estudo levaram em conta a disponibilidade, o custo/benefício e a automatização dos equipamentos (quão menor os interferentes pré-analíticos, melhores os resultados da agregação plaquetária). Para o analisador Multiplate ${ }^{\circledR}$, os 
testes foram processados utilizando o agonista de nome comercial ADPtest ${ }^{\circledR}$ que promove a ativação plaquetária através dos receptores plaquetários de ADP, sendo sensível às drogas inibidoras do receptor $\mathrm{P}_{2 \mathrm{Y}_{12}}{ }^{(31)}$ Este equipamento possui dois pares de eletrodos em cada célula de teste. Os sensores duplicados servem como um controle de qualidade integrado, onde o resultado é validado somente se a correlação entre as medições em cada par de sensores for maior ou igual a 0,98. Além disso, há também o controle de qualidade eletrônico, que mede uma resistência fixa internamente ligada à cada uma das posições em que se conectam os cabos da célula de teste. Consideramos pacientes hiporreativos, aqueles com reatividade plaquetária inferiores a 19 AUC para o Multiplate ${ }^{\circledR}$, sendo este limiar recomendado pela declaração do grupo de especialistas em trombose da ESC sobre o papel dos testes de função plaquetária em pacientes submetidos à intervenção coronariana como preditor de eventos hemorrágicos, sugerido por Sibbing et al. ${ }^{(10)}$

As amostras processadas no sistema PFA-100 ${ }^{\circledR}$ devem ser devidamente homogeneizadas e processadas em analisador hematológico para avaliação da qualidade (o teste é altamente influenciado pelo nível de hematócrito e contagem de plaquetas) e se aprovadas, o material deve ser inserido lentamente no cartucho de teste, sem a formação de bolhas. A análise plaquetária através da medição do tempo de oclusão é realizado em plataforma fechada e de forma automática, dessa forma, uma verificação da calibração do equipamento é realizada diariamente através da execução de ciclos automáticos de avaliação dos sistemas de medição. Não existe um consenso quanto ao intervalo terapêutico ou limiar de risco hemorrágico para os resultados dos testes do PFA $-100^{\circledR}$ para ambos os cartuchos, sendo considerado apenas como hiporreativos os pacientes com tempo de oclusão superior a 299 segundos para o PFA ${ }^{\circledR} \mathrm{P} 2 \mathrm{Y}$ e superior à 116 segundos para o Col/ADP, de acordo com Breet et al. ${ }^{(10,24)}$

\subsection{Análises estatísticas}

As variáveis contínuas foram expressas como média \pm desvio padrão (DP) ou medianas com intervalo interquartíl. Variáveis categóricas foram descritas como frequências absolutas e relativas. O teste do qui-quadrado e o teste da razão de verossimilhança foram usados para associações de variáveis categóricas. 0 
teste de Mann-Whitney e o teste $t$ de Student foram realizados para comparações quantitativas de dados. Os parâmetros clínicos e metabólicos foram comparados entre vale e pico, pelo teste de Wilcoxon e as classificações de inibição plaquetária das diferentes metodologias comparados entre vale e pico pelo teste de McNemar.

Além disso, os parâmetros clínicos basais foram comparados entre pacientes normais versus pacientes hiporreativos pelos testes do qui-quadrado, teste de Fisher ou teste da razão de verossimilhança. A associação ajustada entre os dados laboratoriais e a reatividade plaquetária foi testada com uso de regressão logística múltipla. As variáveis incluídas foram selecionadas por critérios estatísticos (univariada p $<0,05)$ e também por relevância clínica, evitando o sobreajuste do modelo. Todos os testes estatísticos foram bilaterais, e o critério para significância estatística foi $p<0,05$. Todas as análises estatísticas foram realizadas no IBM-SPSS for Windows versão 22.0 . 


\section{RESULTADOS}

A agregabilidade plaquetária dos 50 pacientes incluídos neste estudo foi medida pelo Multiplate $^{\circledR}$ e sistema PFA-100 ${ }^{\circledR}$ através dos cartuchos Innovance ${ }^{\circledR}$ PFA-P2Y e PFA ${ }^{\circledR} \mathrm{Col} / \mathrm{ADP}$. Todos os 50 indivíduos apresentaram resultados válidos para as metodologias estudadas, exceto 2 participantes que tiveram seus resultados prejudicados apenas para o $P F A^{\circledR}$ Col/ADP, devido à perda de dados por erros eletrônicos durante a execução do teste. A mediana do tempo de terapia com ticagrelor até a coleta sanguínea foi de 3 dias [mín.1, máx.11]. As características clínicas e parâmetros laboratoriais da população estudada estão descritos na tabela 1.

Tabela 1. Características clínicas e parâmetros laboratoriais da população estudada

\begin{tabular}{|c|c|}
\hline Características & $\mathbf{N}$ \\
\hline Masculino (\%) & $42(84)$ \\
\hline Idade (média \pm DP) & $59,3( \pm 12,7)$ \\
\hline Índice de massa corpórea (média \pm DP) & $28,4( \pm 3,5)$ \\
\hline \multicolumn{2}{|l|}{ Fatores de risco cardiovascular $n(\%)$} \\
\hline Tabagismo & $9(18)$ \\
\hline Hipertensão arterial sistêmica & $26(52)$ \\
\hline Diabetes mellitus & $14(28)$ \\
\hline Dislipidemia & $22(44)$ \\
\hline \multicolumn{2}{|l|}{ Tipo infarto agudo do miocárdio $\mathrm{n}(\%)$} \\
\hline Sem supra & $28(56)$ \\
\hline Com supra & $22(44)$ \\
\hline Infarto agudo do miocárdio prévio & $12(24)$ \\
\hline \multicolumn{2}{|l|}{ Angioplastia $\mathrm{n}(\%)$} \\
\hline Artéria descendente anterior & $32(64)$ \\
\hline Artéria coronária direita & $20(40)$ \\
\hline Artéria coronária circunflexa & $14(28)$ \\
\hline \multicolumn{2}{|l|}{ Medicações n(\%) } \\
\hline IECA/BRA & $21(42)$ \\
\hline Bloq. canais $\mathrm{Ca}++$ & $5(10)$ \\
\hline Beta Bloqueador & $28(56)$ \\
\hline Enoxaparina & $30(60)$ \\
\hline Hipoglicemiantes & $14(28)$ \\
\hline Dipirona & $26(52)$ \\
\hline \multicolumn{2}{|l|}{ Estatinas $\mathrm{n}(\%)$} \\
\hline Atorvastatina & $14(28)$ \\
\hline Rosuvastatina & $31(62)$ \\
\hline \multicolumn{2}{|l|}{ Exames Laboratoriais Média ( $\pm D P)$} \\
\hline Hemoglobina, g/dL & $14,1( \pm 1,4)$ \\
\hline Plaquetas, $\times 10^{\wedge} 3 / \mathrm{mL}$ & $209,5( \pm 59,2)$ \\
\hline
\end{tabular}




\begin{tabular}{lc}
...continuação & \\
\hline Volume plaquetário mério, fL & $10,5( \pm 0,9)$ \\
Neutrófilos, \% & $67,9( \pm 13,1)$ \\
Creatinina, mg/dL & $1,1( \pm 0,7)$ \\
Glicemia, mg/dL & $133,3( \pm 53,1)$ \\
Colesterol Total, mg/dL & $150,6( \pm 51,4)$ \\
HDL, mg/dL & $38,8( \pm 10,7)$ \\
LDL, mg/dL & $86,3( \pm 46,9)$ \\
Triglicérides, mg/dL & $137,4(60,7)$ \\
Troponina, pg/mL (mediana[mín;máx]) & $17450[77,5 ; 179000]$ \\
Proteína C reativa, mg/dL (mediana[mín;máx]) & $6,7[0,1 ; 360,3]$ \\
Fração Ejeção 1º Ecocardiograma, \% & $55( \pm 11)$ \\
\hline
\end{tabular}

IECA/BRA: Inibidores da enzima conversora de angiotensina/Bloqueadores do receptor de angiotensina. DP: Desvio padrão.

As características clínicas dos grupos hiporreativos e não hiporreativos à ticagrelor, quando mensurado pelo Multiplate $^{\circledR}$, estão comparadas na tabela 2. De modo geral os grupos são semelhantes, com diferenças significativas identificadas apenas para menor quantidade de neutrófilos, e de colesterol total e LDL, no grupo de hiporreativos. Também observamos uma diferença numérica, que não alcançou significância em relação à idade, onde os pacientes hiporreativos eram mais jovens $(57,4 \pm 11,8$ versus $64,8 \pm 14,2$ anos; $p=0,071)$.

Tabela 2. Fatores associados de acordo com a classificação da reatividade plaquetária medida pelo Multiplate ${ }^{\circledR}$ após 2 horas da dose de manutenção de ticagrelor (pico)

\begin{tabular}{lcccc}
\hline Características & $\begin{array}{c}\text { Não } \\
\text { hiporreativos } \\
(\mathbf{n = 1 3 )}\end{array}$ & $\begin{array}{c}\text { Hiporreativos } \\
(\mathbf{n = 3 7 )}\end{array}$ & $\begin{array}{c}\text { Total } \\
(\mathbf{N}=50)\end{array}$ & Valor-p \\
\hline Masculino, $\mathrm{n}(\%)$ & $10(76,9)$ & $32(86,5)$ & $42(84)$ & 0,413 \\
Idade (média $\pm \mathrm{DP})$ & $64,8 \pm 14,2$ & $57,4 \pm 11,8$ & $50(100)$ & 0,071 \\
Índice de massa corpórea (média \pm & $28,1 \pm 3,18$ & $28,5 \pm 3,61$ & $50(100)$ & 0,727 \\
DP) & & & & \\
Fator de risco cardiovascular, n(\%) & $7(53,8)$ & $19(51,4)$ & $26(52)$ & 0,877 \\
$\quad$ Hipertensão arterial sistêmica & $3(23,1)$ & $11(29,7)$ & $14(28)$ & 0,734 \\
Diabetes mellitus & $7(53,8)$ & $15(40,5)$ & $22(44)$ & 0,406 \\
$\quad$ Dislipidemia & & & & \\
Tipo de infarto agudo do miocárdio, & & $17(45,9)$ & $22(44)$ & 0,640 \\
n(\%) & $5(38,5)$ & $10(27,0)$ & $12(24)$ & 0,480 \\
$\quad$ Com supra & $2(15,4)$ & & & \\
$\quad$ Infarto agudo do miocárdio prévio & & $23(62,2)$ & $32(64)$ & 0,347 \\
Angioplastia, n(\%) & $9(69,2)$ & $16(43,2)$ & $20(40)$ & 0,777 \\
$\quad$ Artéria descendente anterior & $4(30,8)$ & $7(18,9)$ & $14(28)$ & 0,206 \\
$\quad$ Artéria coronária direita & $7(53,8)$ & & & continua... \\
Artéria coronária circunflexa & & &
\end{tabular}




\begin{tabular}{|c|c|c|c|c|}
\hline \multicolumn{5}{|l|}{ Medicações, n(\%) } \\
\hline IECA/BRA & $4(30,8)$ & $17(45,9)$ & $21(42)$ & 0,340 \\
\hline Bloq. Ca++ & $3(23,1)$ & $2(5,4)$ & $5(10)$ & 0,103 \\
\hline Beta Bloqueadores & $8(61,5)$ & $20(54,1)$ & $28(56)$ & 0,640 \\
\hline Ácido acetil salicílico & $13(100)$ & $37(100)$ & $50(100)$ & $>0,999$ \\
\hline Enoxaparina & $9(69,2)$ & $21(56,8)$ & $30(60)$ & 0,430 \\
\hline Hipoglicemiantes & $3(23,1)$ & $11(29,7)$ & $14(28)$ & 0,734 \\
\hline Dipirona & $6(46,2))$ & $20(54,1)$ & $26(52)$ & 0,624 \\
\hline Estatinas & $13(100)$ & $34(91,9)$ & $47(94)$ & 0,558 \\
\hline \multicolumn{5}{|l|}{ Exames laboratoriais, média $\pm \mathrm{DP}$} \\
\hline Hemoglobina, g/dL & $13,6 \pm 1,6$ & $14,3 \pm 1,3$ & $50(100)$ & 0,116 \\
\hline Plaquetas, $x 10^{\wedge} 3 / \mathrm{mL}$ & $220,3 \pm 66,0$ & $205,6 \pm 57,0$ & $49(98)$ & 0,448 \\
\hline Volume plaquetário médio, fL & $10,7 \pm 0,96$ & $10,5 \pm 1,0$ & $49(98)$ & 0,492 \\
\hline Neutrófilos, \% & $74,1 \pm 10,95$ & $65,7 \pm 13,3$ & $49(98)$ & 0,047 \\
\hline Creatinina, mg/dL & $1,1 \pm 0,5$ & $1,1 \pm 0,7$ & $50(100)$ & 0,987 \\
\hline Glicemia, mg/dL & $147,4 \pm 74,7$ & $128,3 \pm 43,0$ & $49(98)$ & 0,270 \\
\hline Colesterol Total, mg/dL & $188,0 \pm 62,0$ & $137,2 \pm 40,5$ & $34(68)$ & 0,009 \\
\hline $\mathrm{HDL}, \mathrm{mg} / \mathrm{dL}$ & $40,7 \pm 17,4$ & $38,1 \pm 7,5$ & $34(68)$ & 0,676 \\
\hline $\mathrm{LDL}, \mathrm{mg} / \mathrm{dL}$ & $120,3 \pm 57,3$ & $74,0 \pm 36,7$ & $34(68)$ & 0,009 \\
\hline Triglicérides, mg/dL & $137,2 \pm 64,4$ & $137,2 \pm 60,7$ & $34(68)$ & 0,990 \\
\hline $\begin{array}{l}\text { Troponina, pg/mL (mediana } \\
\text { [mín;máx]) }\end{array}$ & $\begin{array}{c}7650[109 ; 152000 \\
]\end{array}$ & $18000[77,5 ; 179.000]$ & $50(100)$ & 0,877 \\
\hline Proteína $\mathrm{C}$ reativa, $\mathrm{mg} / \mathrm{dL}$ & $95,4 \pm 146,5$ & $21,9 \pm 66,6$ & $32(64)$ & 0,489 \\
\hline $\begin{array}{l}\text { Fração Ejeção 1ำ } \\
\text { Ecocardiograma, } \mathrm{n}(\%)\end{array}$ & $0,5 \pm 0,1$ & $0,6 \pm 0,1$ & $49(98)$ & 0,088 \\
\hline
\end{tabular}

DP: Desvio padrão. IECA/BRA: Inibidores da enzima conversora de angiotensina/Bloqueadores do receptor de angiotensina.

Parâmetros associados à hiporreatividade medida pelo Multiplate ${ }^{\circledR}$, como neutrófilos, colesterol total e LDL colesterol, não se mantiveram quando a hiporreatividade foi medida pelo $P F A^{\circledR} P 2 Y$. Outros parâmetros foram associados à hiporreatividade quando medida pelo $P F A^{\circledR} P 2 Y$, como IMC $(p=0,021)$, troponina $(p=0,004)$ e fração de ejeção $(p=0,035)$ (Tabela 3$)$.

Tabela 3. Fatores associados de acordo com a classificação da reatividade plaquetária medida pelo PFA ${ }^{\circledR}$ P2Y após $2 h$ da dose de manutenção de ticagrelor (pico)

\begin{tabular}{|c|c|c|c|c|}
\hline Características & $\begin{array}{c}\text { Não hiporreativos } \\
(n=7)\end{array}$ & $\begin{array}{l}\text { Hiporreativos } \\
(n=43)\end{array}$ & $\begin{array}{c}\text { Total } \\
(n=50)\end{array}$ & Valor-p \\
\hline Masculino $\mathrm{n}(\%)$ & $5(71,4)$ & $37(86,0)$ & $42(84)$ & 0,310 \\
\hline Idade (média $\pm \mathrm{DP}$ ) & $62,1 \pm 13,4$ & $58,8 \pm 12,7$ & $50(100)$ & 0,530 \\
\hline $\begin{array}{l}\text { Índice de massa corpórea } \\
\text { (média } \pm \text { DP) }\end{array}$ & $25,6 \pm 1,7$ & $28,9 \pm 3,5$ & $50(100)$ & 0,021 \\
\hline \multicolumn{5}{|l|}{ Fator de risco cardiovascular, $\mathrm{n}(\%)$} \\
\hline Hipertensão arterial sistêmica & $2(28,6)$ & $24(55,8)$ & $26(52)$ & 0,239 \\
\hline Diabetes mellitus & $4(57,1)$ & $10(23,3)$ & $14(28)$ & 0,085 \\
\hline
\end{tabular}




\begin{tabular}{|c|c|c|c|c|}
\hline $\begin{array}{l}\text { Dislipidemia } \\
\text { Tipo de infarto agudo do miocárdio, } \\
\mathrm{n}(\%)\end{array}$ & $3(42,9)$ & $19(44,2)$ & $22(44)$ & $>0,999$ \\
\hline Com supra & $3(42,9)$ & $19(44,2)$ & $22(44)$ & $>0,999$ \\
\hline Infarto agudo do miocárdio prévio & $0(0,0)$ & $12(27,9)$ & $12(24)$ & 0,174 \\
\hline \multicolumn{5}{|l|}{ Angioplastia, n(\%) } \\
\hline Artéria descendente anterior & $7(100)$ & $25(58,1)$ & $32(64)$ & 0,076 \\
\hline Artéria coronária direita & $1(14,3)$ & $19(44,2)$ & $20(40)$ & 0,182 \\
\hline Artéria coronária circunflexa & $0(0,0)$ & $14(32,6)$ & $14(28)$ & 0,068 \\
\hline \multicolumn{5}{|l|}{ Medicações, n(\%) } \\
\hline IECA/BRA & $5(71,4)$ & $16(37,2)$ & $21(42)$ & 0,115 \\
\hline Bloq. $\mathrm{Ca}++$ & $0(0,0)$ & $5(11,6)$ & $5(10)$ & $>0,999$ \\
\hline Beta Bloqueadores & $5(71,4)$ & $23(53,5)$ & $28(56)$ & 0,444 \\
\hline Ácido acetil salicílico & $7(100,0)$ & $43(100)$ & $50(100)$ & $>0,999$ \\
\hline Enoxaparina & $4(57,1)$ & $26(60,5)$ & $30(60)$ & $>0,999$ \\
\hline Hipoglicemiantes & $3(42,9)$ & $11(25,6)$ & $14(28)$ & 0,384 \\
\hline Dipirona & $3(42,9)$ & $23(53,5)$ & $26(52)$ & 0,697 \\
\hline Estatinas & $7(100)$ & $40(93)$ & $47(94)$ & $>0,999$ \\
\hline \multicolumn{5}{|l|}{ Exames Laboratoriais, média $\pm \mathrm{DP}$} \\
\hline Hemoglobina, g/dL & $13,5 \pm 1,2$ & $14,3 \pm 1,4$ & $50(100)$ & 0,171 \\
\hline Plaquetas, $\times 10^{\wedge} 3 / \mathrm{mL}$ & $173,9 \pm 34,6$ & $215,4 \pm 60,6$ & $49(98)$ & 0,085 \\
\hline Volume plaquetário médio, fL & $10,7 \pm 0,7$ & $10,5 \pm 1,0$ & $49(98)$ & 0,541 \\
\hline Neutrófilos, \% & $73,1 \pm 7,5$ & $67,1 \pm 13,7$ & $49(98)$ & 0,265 \\
\hline Creatinina, mg/dL & $1,1 \pm 0,4$ & $1,1 \pm 0,7$ & $50(100)$ & 0,811 \\
\hline Glicemia, mg/dL & $138,3 \pm 53,8$ & $132,5 \pm 53,6$ & $49(98)$ & 0,793 \\
\hline Colesterol Total, mg/dL & $165,3 \pm 33,8$ & $147,2 \pm 54,4$ & $34(68)$ & 0,448 \\
\hline $\mathrm{HDL}, \mathrm{mg} / \mathrm{dL}$ & $34,7 \pm 5,5$ & $39,6 \pm 11,5$ & $34(68)$ & 0,311 \\
\hline $\mathrm{LDL}, \mathrm{mg} / \mathrm{dL}$ & $105 \pm 27,7$ & $82,3 \pm 49,6$ & $34(68)$ & 0,289 \\
\hline Triglicérides, mg/dL & $139,5 \pm 95,3$ & $137 \pm 53,1$ & $34(68)$ & 0,953 \\
\hline $\begin{array}{l}\text { Troponina, pg/mL } \\
\text { (mediana[mín;máx]) }\end{array}$ & $106000[1170 ; 179000]$ & $7650[78 ; 143.000]$ & $50(100)$ & 0,004 \\
\hline Proteína $\mathrm{C}$ reativa, mg/dL & $5,1 \pm 4,6$ & $50,6 \pm 108,3$ & $32(64)$ & 0,392 \\
\hline Fração Ejeção 10 Ecocardiograma & $0,5 \pm 0,1$ & $0,6 \pm 0,1$ & $49(98)$ & 0,035 \\
\hline
\end{tabular}

IECA/BRA: Inibidores da enzima conversora de angiotensina/Bloqueadores do receptor de angiotensina.

Realizamos três modelos multivariados para testar a associação de variáveis clínicas selecionadas e a hiporreatividade plaquetária mensurada por Multiplate (Tabela 4). A única variável que se associou de forma independente à hiporreatividade foi a taxa de neutrófilos circulantes (OR 0,86; IC 95\% 0,77-0,97; $\mathrm{p}=0,014)$. 
Tabela 4. Análise multivariada ajustada para idade e sexo

\begin{tabular}{lcccc}
\hline \multirow{2}{*}{ Variável } & OR & \multicolumn{2}{c}{ IC (95\%) } & \multirow{2}{*}{ Valor-p } \\
\cline { 3 - 4 } & & Inferior & Superior & 0,949 \\
Idade & 1,00 & 0,94 & 1,07 & 0,831 \\
Sexo & 0,76 & 0,07 & 9,01 & 0,963 \\
LDL & 1,00 & 0,98 & 1,02 & 0,810 \\
\hline Idade & 0,99 & 0,93 & 1,06 & 0,859 \\
Sexo & 1,19 & 0,17 & 8,13 & 0,252 \\
Hemoglobina & 1,45 & 0,77 & 2,74 & 0,296 \\
Idade & 0,96 & 0,89 & 1,04 & 0,335 \\
Sexo & 0,29 & 0,02 & 3,65 & 0,014 \\
Neutrófilos & 0,86 & 0,77 & 0,97 & \\
\hline
\end{tabular}

Para cada um dos métodos testados, a comparação das medições de agregabilidade plaquetária entre pico e vale de ação de ticagrelor não apresentaram diferenças significativas (Figura 6) quando medida respectivamente pelo Multiplate ${ }^{\circledR}$ $14 \pm 6$ AUC versus $13 \pm 7$ AUC, $p=0,101$ ); pelo PFA ${ }^{\circledR} P 2 Y 300$ s $[71 ; 300]$ versus 300s [53;300], $p=0,286$; e pelo PFA ${ }^{\circledR}$ Col/ADP 101s [64;300] versus 125 s [59;300], $p=0,347$. 

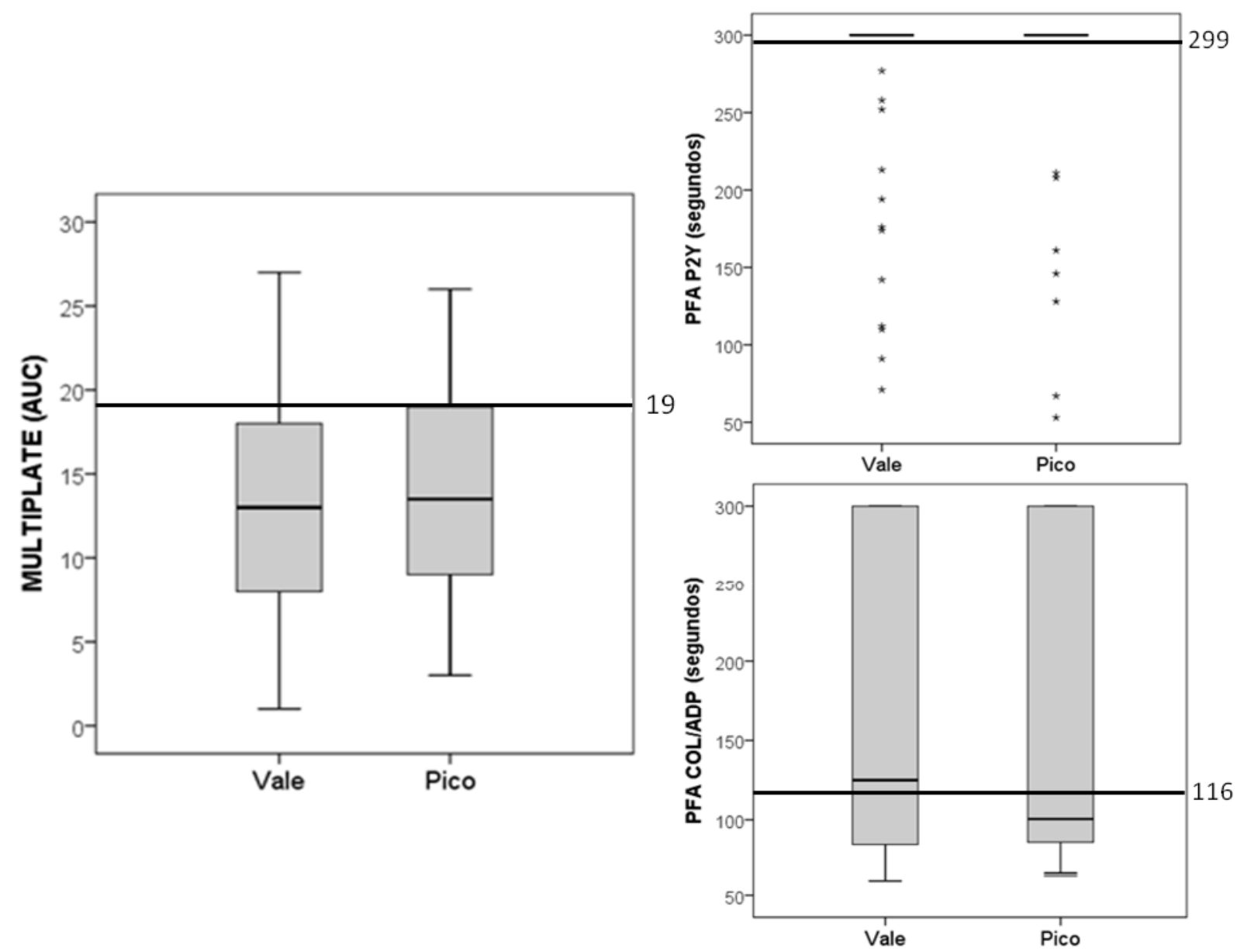

Figura 6. Resultado dos testes Multiplate ${ }^{\circledR}$ ADP (expresso em AUC); PFA ${ }^{\circledR}$ P2Y e PFA ${ }^{\circledR}$ Col/ADP (expresso em segundos) no vale e pico do ticagrelor

De modo semelhante, para cada um dos métodos testados, a comparação da prevalência de hiporreatividade plaquetária foi semelhante entre pico e vale de ação de ticagrelor (Figura 7) medida pelo PFA ${ }^{\circledR} P 2 Y(86 \%$ versus $76 \%, p=0,34)$, pelo Multiplate ${ }^{\circledR}(74 \%$ versus $82 \%, p=0,09)$ e pelo PFA ${ }^{\circledR}$ Col/ADP (48\% versus $52 \%$, $p=0,71)$, respectivamente.

A comparação da prevalência de hiporreatividade plaquetária entre os métodos, tanto no pico quanto no vale de ação de ticagrelor, demostrou que o Multiplate ${ }^{\circledR}$ e o PFA ${ }^{\circledR} \mathrm{P} 2 \mathrm{Y}$ não apresentaram diferenças entre si (respectivamente, para pico $74 \%$ versus $86 \%, p=0,210$; e para vale $82 \%$ versus $76 \%, p=0,581$ ). Entretanto, 0 PFA ${ }^{\circledR} \mathrm{Col} / \mathrm{ADP}$ apresentou menor prevalência, tanto no pico quanto no vale de ação de ticagrelor, comparado ao Multiplate ${ }^{\circledR}$ (respectivamente para pico $48 \%$ versus $74 \%$, $\mathrm{p}=0,023$; e para vale $52 \%$ versus $82 \%, \mathrm{p}=0,004)$ e também ao $\mathrm{PFA}^{\circledR} \mathrm{P} 2 \mathrm{Y}$ 
(respectivamente para pico $48 \%$ versus $86 \%$, $p<0,001$; e para vale $52 \%$ versus $76 \%$, $p=0,035)$.

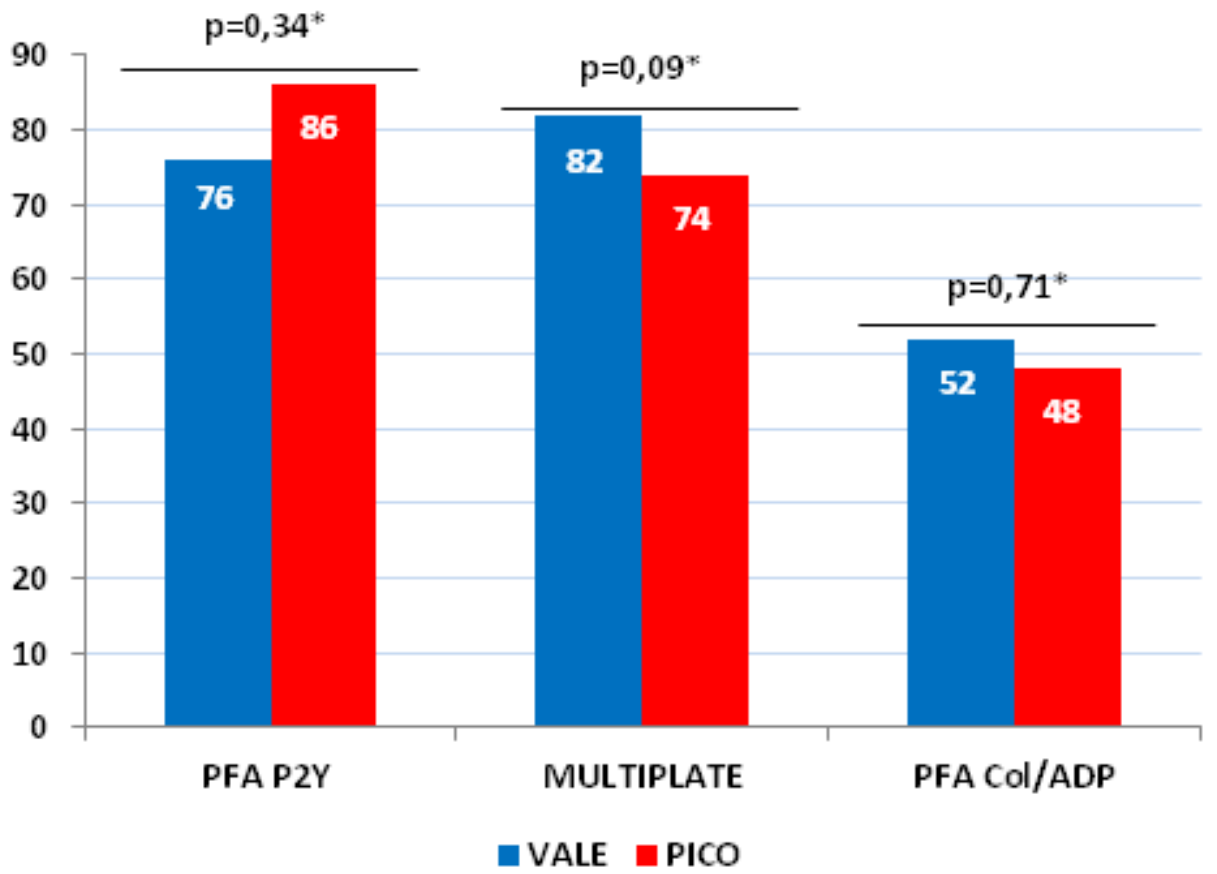

$\left(^{*}\right)$ Comparação da prevalência de hiporreatividade entre pico e vale para o mesmo método.

Prevalência de hiporreatividade plaquetária por metodologias

Figura 7. Prevalência de hiporreatividade plaquetária por metodologias 


\section{DISCUSSÃO}

Em nosso estudo demonstramos que pacientes com IAM tratados com ticagrelor e AAS apresentaram alta prevalência de hiporreatividade plaquetária no vale e no pico do efeito de ticagrelor. A prevalência de hiporreatividade plaquetária medida pelos métodos Multiplate ${ }^{\circledR}$ e $P F A^{\circledR} P 2 Y$ foram semelhantes, porém, quando medida pelo PFA ${ }^{\circledR} \mathrm{Col} / \mathrm{ADP}$, a prevalência foi cerca de $30 \%$ mais baixa.

A reatividade plaquetária em pacientes portadores de SCA com tratamento duplo antiplaquetário é um relevante fator de risco para a ocorrência de eventos trombóticos e/ou hemorrágicos após os procedimentos de intervenção coronariana. $^{(14)}$ As complicações hemorrágicas estão fortemente associadas ao óbito nas SCAs, e o risco da ocorrência de sangramentos durante o tratamento com drogas antiplaquetárias é maior em subgrupos clinicamente mais vulneráveis (idosos, baixo peso corporal, insuficiência renal e etc.). ${ }^{(40)}$ Com o surgimento de potentes inibidores plaquetários, tais como o ticagrelor e prasugrel, há um risco de sangramento aumentado, concomitante a um grau de inibição plaquetária mais elevado durante o tratamento. Por outro lado, as altas taxas de hiporreatividade plaquetária que encontramos em pacientes com IAM tratados com ticagrelor e AAS, tanto em nosso estudo, como em estudos prévios (i.e. $75-80 \%$ ) não são proporcionais às taxas de sangramentos em pacientes com SCA tratados com ticagrelor no estudo PLATO (i.e. $\sim 16 \%$ - sangramento major e minor), sugerindo que o risco hemorrágico nesse cenário não seja dependente apenas da hiporreatividade plaquetária, mas sim de uma interação entre aspectos laboratoriais e o risco clínico global do individuo. ${ }^{(16,41,42)}$

Importante enfatizar que nossos achados acerca da prevalência da hiporreatividade plaquetária em pacientes tratados com ticagrelor estão de acordo com achados de estudos prévios, que utilizaram outras metodologias laboratoriais no mesmo tipo de população. Em um estudo derivado do PLATO que testou a resposta plaquetária no tratamento de 69 pacientes com clopidogrel versus ticagrelor e comparou os resultados no vale e pico das drogas em três metodologias (PRP [ADP $20 \mu \mathrm{M}$ e ADP $5 \mu \mathrm{M}$ ], VASP e VerifyNow), o ticagrelor apresentou maior inibição plaquetária em todos os métodos, atingindo raros casos de hiperreatividade. Nesse subestudo, apesar de não ser o objetivo dos autores avaliar e discutir a prevalência de hiporreatividade plaquetária, considerando um cuttoff $<85$ PRU para a metodologia 
VerifyNow (conforme sugerido por Gianluca Campo et al.), nota-se uma prevalência de 91\% de hiporreatividade secundária ao ticagrelor e 9\% secundária ao clopidogrel no pico de ação de ambos os fármacos. ${ }^{(43,44)}$ Adicionalmente, em um subestudo do PEGASUS-TIMI 54 em pacientes coronariopatas na fase clínica estável e crônica, a reatividade plaquetária dos pacientes foi testada com duas doses de ticagrelor $(60 \mathrm{mg} \mathrm{e}$ 90mg) e comparadas ao placebo. Ambas as doses de ticagrelor tiveram níveis de inibição plaquetária igualmente eficazes e foram raros os casos de reatividade residual. A reatividade plaquetária sob efeito da dose $90 \mathrm{mg}$ foi numericamente inferior à $60 \mathrm{mg}$ e, apesar da comparação não ter alcançado significância estatística (respectivamente, $20 \pm 19$ versus $29 \pm 39 \mathrm{PRU}, \mathrm{p}=0,73$ ), os dados sugerem altas taxas de hiporreatividade em ambas as doses de ticagrelor, sendo $100 \%$ para $90 \mathrm{mg}$ e $91 \%$ para $60 \mathrm{mg}$ abaixo do cuttoff sugerido de 85 PRU. ${ }^{(45)}$ Portanto, em alinhamento com evidências prévias, nossos achados sugerem uma acentuada inibição plaquetária com ticagrelor 90mg, que possivelmente esteja fora da janela de risco/benefício ideal. Além disso, demonstramos que a hiporreatividade plaquetária ocorre antes e após a dose matinal de ticagrelor de forma semelhante, o que sugere um efeito inibitório residual, mesmo no vale do efeito do fármaco.

Do ponto de vista clínico, evidências de estudos randomizados e observacionais que compararam o ticagrelor a outras drogas inibidoras do receptor

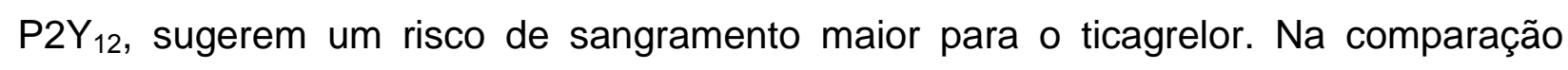
entre ticagrelor e prasugrel por uma metanálise, a superioridade do prasugrel foi evidenciada pela redução de IAM (OR=0,54; IC 95\% 0,29-0,99; $p=0,05)$ e menor taxa de sangramento de forma significativa (OR=0,75; IC 95\% 0,59-0,95; $p=0,02){ }^{(41)}$ Quando comparado ao clopidogrel em um estudo observacional com 45.206 pacientes do registro Swedeheart, o ticagrelor foi associado a um baixo risco de ocorrência do desfecho combinado (morte, IAM ou AVC), no entanto, a taxa de eventos hemorrágicos foram significativamente maiores $\left(2,9 \%\right.$ versus $2,3 \%$; $H R=1,27$; IC 95\% 1,09-1,48). ${ }^{(46)}$ Adicionalmente, um subestudo do PEGASUS-TIMI 54 demonstrou que a descontinuação precoce do ticagrelor foi motivada principalmente por sangramento e dispneia. A taxa de descontinuação foi maior nos grupos de tratamento padrão 90mg (32\%), seguida do grupo 60mg (29\%) em relação ao placebo (21\%). Essa diferença foi mais acentuada nos primeiros 90 dias após randomização, com taxas de descontinuação em 1 ano de $24,1 \%, 19,8 \%$ e 13,1\% nos braços de $90 \mathrm{mg}$, 60mg e placebo, respectivamente. ${ }^{(40,47)}$ 
Do ponto de vista laboratorial, o Multiplate ${ }^{\circledR}$ e o PFA ${ }^{\circledR} \mathrm{P} 2 \mathrm{Y}$ não apresentaram diferença na mensuração da prevalência de hiporreatividade plaquetária no pico e no vale do ticagrelor. $O P F{ }^{\circledR} P 2 Y$ se destina à detecção exclusiva do bloqueio dos receptores plaquetários $\mathrm{P}_{2} \mathrm{Y}_{12}$, diferente do teste $\mathrm{PFA}{ }^{\circledR} \mathrm{Col} / \mathrm{ADP}$, que apresenta menor especificidade para a detecção da inibição dos receptores $\mathrm{P}_{2} \mathrm{Y}_{12}$, e isso poderia explicar a diferença significativa encontrada na menor prevalência da hiporreatividade medida por esse cartucho. A metodologia utilizada pelo equipamento Multiplate ${ }^{\circledR}$, além de ter sido estudada em grandes ensaios clínicos, nos forneceu resultados condizentes com o contexto terapêutico. Devido a existência de um cuttoff recomendado para estratificação do risco hemorrágico, ${ }^{(27)}$ os resultados liberados pelo Multiplate ${ }^{\circledR}$ contribuem para uma avaliação quantitativa da inibição plaquetária e estão de acordo com os resultados dos estudos plaquetários derivados do PEGASUS-TIMI 54 e PLATO. Entre os parâmetros laboratoriais incluídos em análise multivariada, apenas os neutrófilos apresentaram associação independente com a reatividade plaquetária. Indivíduos com maior taxa de neutrófilos apresentam-se menos hiporreativos, sendo assim, sugere-se que a contagem de neutrófilos estando diretamente ligada ao estado inflamatório do indivíduo, as alterações hemostáticas prótrombóticas que ocorrem durante um desequilíbrio podem influenciar a atividade plaquetária. $^{(48)}$

Nosso estudo apresenta limitações relevantes. Trabalhamos com uma pequena amostra de pacientes e, portanto algumas características clínicas não apresentaram associação com a hiporreatividade plaquetária, possivelmente por falta de poder. Um exemplo é a idade numericamente diferente entre os grupos analisados, porém, sem diferença estatística, e por esse motivo incluímos a idade em todos os modelos ajustados. Além disso, utilizamos dois testes de avaliação da função plaquetária de metodologias e especificidades diferentes para detecção da responsividade a inibidores do receptor de ADP. Os resultados apresentados possuem unidades de medidas numericamente não comparáveis entre si. No entanto, todos os testes sugerem uma elevada taxa de hiporreatividade plaquetária na população estudada.

Estudos futuros são necessários para avaliar a associação entre a hiporreatividade plaquetária com ticagrelor e risco hemorrágico e, se doses menores do fármaco poderiam atenuar a hiporreatividade plaquetária, e possivelmente reduzir o risco hemorrágico de pacientes com IAM. 


\section{CONCLUSÕES}

1. Pacientes com infarto agudo do miocárdio apresentaram alta prevalência de hiporreatividade plaquetária no tratamento com ticagrelor, tanto no vale quanto no pico do fármaco;

2. A hiporreatividade plaquetária foi mais prevalente quando aferida pelo Multiplate ${ }^{\circledR}$ e PFA ${ }^{\circledR} \mathrm{P} 2 \mathrm{Y}$, em comparação com o PFA ${ }^{\circledR} \mathrm{Col} / \mathrm{ADP}$ provavelmente devido a menor especificidade desse teste à inibição dos receptores P2Y ${ }_{12}$;

3. Dentre as características clínicas e laboratoriais avaliadas, apenas os neutrófilos apresentaram associação independente com a hiporreatividade plaquetária no tratamento com ticagrelor. 


\section{REFERÊNCIAS}

1. Santos J, Meira KC, Camacho AR, Salvador PT, Guimarães RM, Pierin ÂM, et al. Mortalidade por infarto agudo do miocárdio no Brasil e suas regiões geográficas: análise do efeito da idade-período-coorte. Ciên Saúde Colet. 2018;23(5):1621-34.

2. Baena CP, Olandoski M, Luhm KR, Costantini CO, Guarita-Souza LC, Faria-Neto JR. Tendência de mortalidade por infarto agudo do miocárdio em Curitiba (PR) no período de 1998 a 2009. Arq Bras Cardiol. 2012;98(3):211-7.

3. Pesaro AE, Serrano CV Jr, Nicolau JC. Infarto agudo do miocárdio- síndrome coronariana aguda com supradesnível do segmento ST. Rev Assoc Med Bras (1992). 2004;50(2):214-20.

4. Nicolau J, Timerman A, Marin-Neto J, Piegas L, Dornas C, Franci A, et al. Diretrizes da Sociedade Brasileira de Cardiologia sobre Angina Instável e Infarto Agudo do Miocárdio sem Supradesnível do Segmento ST (II Edição, 2007) - Atualização 2013/2014. Arq Bras Cardiol. 2014;102(3Supl. 1):1-61.

5. Giroldo M L, Alves AS, Baptista F. Doença aterosclerótica: uma patologia multi-fatorial. SaBios-Rev Saúde e Biol. 2007;2(1):32-41.

6. Silva MA, Sousa AG, Schargodsky $H$. Fatores de risco para infarto do miocárdio no Brasil: estudo FRICAS. Arq Bras Cardiol. 1998;71(5):667-75.

7. Gottlieb MG, Bonardi G, Moriguchi EH. Fisiopatologia e aspectos inflamatórios da aterosclerose. Sci Med (Porto Alegre). 2005;15(3):203-7.

8. Bode C, Frey M. Infarto agudo de miocardio. In: Runge MS, Ohman EM, editors. Netter Cardiología. Barcelona: Elsevier; 2006. p. 93-102.

9. Gremmel T, Frelinger AL, Michelson AD. Platelet Physiology. Semin Thromb Hemost. 2016;42(3):191-204.

10. Sibbing D, Schulz S, Braun S, Morath T, Stegherr J, Mehilli J, et al. Antiplatelet effects of clopidogrel and bleeding in patients undergoing coronary stent placement. J Thromb Haemost. 2010;8(2):250-6.

11. Fox KA, Mehta SR, Peters R, Zhao F, Lakkis N, Gersh BJ, et al.; Clopidogrel in Unstable angina to prevent Recurrent ischemic Events Trial. Benefits and risks of the combination of clopidogrel and aspirin in patients undergoing surgical revascularization for non-ST-elevation acute coronary syndrome: the Clopidogrel in Unstable angina to prevent Recurrent ischemic Events (CURE) Trial. Circulation. 2004;110(10):1202-8.

12. Yusuf S, Zhao F, Mehta SR, Chrolavicius S, Tognoni G, Fox KK. Effects of clopidogrel in addition to aspirin in patients with acute coronary syndromes without ST-segment elevation. $\mathrm{N}$ Engl J Med. 2001;345(7):494-502.

13. Wiviott SD, Braunwald E, McCabe CH, Montalescot G, Ruzyllo W, Gottlieb S, et al. Prasugrel versus clopidogrel in patients with acute coronary syndromes. $\mathrm{N}$ Engl $\mathrm{J}$ Med. 2007;357(20):2001-15.

14. Tantry US, Bonello L, Aradi D, Price MJ, Jeong YH, Angiolillo DJ, et al.; Working Group on On-Treatment Platelet Reactivity. Consensus and update on the definition of on-treatment 
platelet reactivity to adenosine diphosphate associated with ischemia and bleeding. J Am Coll Cardiol. 2013;62(24):2261-73.

15. Motovska Z, Ondrakova M, Bednar F, Knot J, Ulman J, Maly M. Selection of P2Y12 antagonist, treatment initiation, and predictors of high on-treatment platelet reactivity in a "Real World" registry. Thromb Res. 2015;135(6):1093-9.

16. Wallentin L, Becker RC, Budaj A, Cannon CP, Emanuelsson H, Held C, et al.; PLATO Investigators. Ticagrelor versus clopidogrel in patients with acute coronary syndromes. N Engl J Med. 2009;361(11):1045-57.

17. Piegas L, Timerman A, Feitosa G, Nicolau J, Mattos L, Andrade M, et al. V Diretriz da Sociedade Brasileira de Cardiologia sobre tratamento do infarto agudo do miocárdio com supradesnível do segmento ST. Arq Bras Cardiol. 2015;105(2 Supl.1):1-105.

18. Husted S, James S, Becker RC, Horrow J, Katus H, Storey RF, et al.; PLATO study group. Ticagrelor versus clopidogrel in elderly patients with acute coronary syndromes: a substudy from the prospective randomized PLATelet inhibition and patient Outcomes (PLATO) trial. Circ Cardiovasc Qual Outcomes. 2012;5(5):680-8.

19. Bonaca MP, Bhatt DL, Cohen M, Steg PG, Storey RF, Jensen EC, et al.; PEGASUS-TIMI 54 Steering Committee and Investigators. Long-term use of ticagrelor in patients with prior myocardial infarction. N Engl J Med. 2015;372(19):1791-800.

20. Paniccia R, Priora R, Liotta AA, Abbate R. Platelet function tests: a comparative review. Vasc Health Risk Manag. 2015;11:133-48.

21. Cattaneo M. Light transmission aggregometry and ATP release for the diagnostic assessment of platelet function. Semin Thromb Hemost. 2009;35(2):158-67.

22. Merolla M, Nardi MA, Berger JS. Centrifugation speed affects light transmission aggregometry. Int J Lab Hematol. 2012;34(1):81-5.

23. Simone N, Sarode R, Yates S, Matevosyan K, Reddy M, Gavva C, et al. The role of whole blood platelet aggregation studies in the diagnosis of unexplained bleeding tendencies [abstract]. Blood. 2015;126(23):2260.

24. Breet NJ, van Werkum JW, Bouman HJ, Kelder JC, Ruven HJ, Bal ET, et al. Comparison of platelet function tests in predicting clinical outcome in patients undergoing coronary stent implantation. JAMA. 2010;303(8):754-62.

25. Price MJ, Berger PB, Teirstein PS, Tanguay JF, Angiolillo DJ, Spriggs D, et al.; GRAVITAS Investigators. Standard- vs high-dose clopidogrel based on platelet function testing after percutaneous coronary intervention: the GRAVITAS randomized trial. JAMA. 2011;305(11):1097-105.

26. Collet JP, Cuisset T, Rangé G, Cayla G, Elhadad S, Pouillot C, et al.; ARCTIC Investigators. Bedside monitoring to adjust antiplatelet therapy for coronary stenting. N Engl J Med. 2012;367(22):2100-9.

27. Aradi D, Storey RF, Komócsi A, Trenk D, Gulba D, Kiss RG, et al.; Working Group on Thrombosis of the European Society of Cardiology. Expert position paper on the role of platelet function testing in patients undergoing percutaneous coronary intervention. Eur Heart $\mathrm{J}$. 2014;35(4):209-15. 
28. Gupta R, Kirtane AJ, Ozan MO, Witzenbichler B, Rinaldi MJ, Metzger DC, et al. Platelet reactivity and clinical outcomes after coronary artery implantation of drug-eluting stents in subjects with peripheral arterial disease: analysis from the ADAPT-DES study (Assessment of Dual Antiplatelet Therapy With Drug-Eluting Stents). Circ Cardiovasc Interv. 2017; 10(3):e004904.

29. Gurbel PA, Becker RC, Mann KG, Steinhubl SR, Michelson AD. Platelet function monitoring in patients with coronary artery disease. J Am Coll Cardiol. 2007;50(19):1822-34.

30. Orban M, Sibbing D. Multiplate Analyzer. In: Waksman R, Gurbel PA, Gaglia Jr MA, editors. Antiplatelet therapy in Cardiovascular Disease. Chichester: Wiley Blackwell. p. 82-91.

31. Sibbing D, Braun S, Jawansky S, Vogt W, Mehilli J, Schömig A, et al. Assessment of ADPinduced platelet aggregation with light transmission aggregometry and multiple electrode platelet aggregometry before and after clopidogrel treatment. Thromb Haemost. 2008;99(1):121-6.

32. Sibbing D, Braun S, Morath T, Mehilli J, Vogt W, Schömig A, et al. Platelet reactivity after clopidogrel treatment assessed with point-of-care analysis and early drug-eluting stent thrombosis. J Am Coll Cardiol. 2009;53(10):849-56.

33. Scavone M, Germanovich K, Femia EA, Cattaneo M. Usefulness of the INNOVANCE PFA P2Y test cartridge for the detection of patients with congenital defects of the platelet P2Y 12 receptor for adenosine diphosphate. Thromb Res. 2014;133(2):254-6.

34. Hayward CP, Harrison P, Cattaneo M, Ortel TL, Rao AK; Platelet Physiology Subcommittee of the Scientific and Standardization Committee of the International Society on Thrombosis and Haemostasis. Platelet function analyzer (PFA)-100 closure time in the evaluation of platelet disorders and platelet function. J Thromb Haemost. 2006;4(2):312-9.

35. Golanski J, Pluta J, Baraniak J, Watala C. Limited usefulness of the PFA-100 for the monitoring of ADP receptor antagonists-in vitro experience. Clin Chem Lab Med. 2004;42(1):25-9.

36. Karger R, Reuter K, Rohlfs J, Nimsky C, Claro U, \& Kretschmer V. The Platelet Function Analyzer (PFA-100) as a Screening Tool in Neurosurgery. ISRN Hematology , 2012 , 1-7.

37. Favaloro EJ. Clinical application of the PFA-100. Curr Opin Hematol. 2002;9(5):407-15.

38. Thygesen K, Alpert JS, Jaffe AS, Simoons ML, Chaitman BR, White HD; Task Force for the Universal Definition of Myocardial Infarction. Third universal definition of myocardial infarction. Nat Rev Cardiol. 2012;9(11):620-33.

39. Kaiser AF, Neubauer H, Franken CC, Krüger JC, Mügge A, Meves SH. Which is the best anticoagulant for whole blood aggregometry platelet function testing? Comparison of six anticoagulants and diverse storage conditions. Platelets. 2012;23(5):359-67.

40. Mehran R, Pocock SJ, Stone GW, Clayton TC, Dangas GD, Feit F, et al. Associations of major bleeding and myocardial infarction with the incidence and timing of mortality in patients presenting with non-ST-elevation acute coronary syndromes: a risk model from the ACUITY trial. Eur Heart J. 2009;30(12):1457-66.

41. Watti H, Dahal K, Zabher HG, Katikaneni P, Modi K, Abdulbaki A. Comparison of prasugrel and ticagrelor in patients with acute coronary syndrome undergoing percutaneous coronary 
intervention: A meta-analysis of randomized and non-randomized studies. Int $\mathrm{J}$ Cardiol. 2017;249:66-72.

42. Cuisset T, Grosdidier C, Loundou AD, Quilici J, Loosveld M, Camoin L, et al. Clinical implications of very low on-treatment platelet reactivity in patients treated with thienopyridine: the POBA study (predictor of bleedings with antiplatelet drugs). JACC Cardiovasc Interv. 2013;6(8):854-63.

43. Storey RF, Angiolillo DJ, Patil SB, Desai B, Ecob R, Husted S, et al. Inhibitory effects of ticagrelor compared with clopidogrel on platelet function in patients with acute coronary syndromes: the PLATO (PLATelet inhibition and patient Outcomes) PLATELET substudy. J Am Coll Cardiol. 2010;56(18):1456-62.

44. Campo G, Parrinello G, Ferraresi P, Lunghi B, Tebaldi M, Miccoli M, et al. Prospective evaluation of on-clopidogrel platelet reactivity over time in patients treated with percutaneous coronary intervention relationship with gene polymorphisms and clinical outcome. J Am Coll Cardiol. 2011;57(25):2474-83.

45. Storey RF, Angiolillo DJ, Bonaca MP, Thomas MR, Judge HM, Rollini F, et al. Platelet Inhibition With Ticagrelor $60 \mathrm{mg}$ Versus $90 \mathrm{mg}$ Twice Daily in the PEGASUS-TIMI 54 Trial. J Am Coll Cardiol. 2016;67(10):1145-54.

46. Edfors R, Sahlén A, Szummer K, Renlund H, Evans M, Carrero JJ, et al. Outcomes in patients treated with ticagrelor versus clopidogrel after acute myocardial infarction stratified by renal function. Heart. 2018;104(19):1575-82.

47. Bonaca MP, Bhatt DL, Oude Ophuis T, Steg PG, Storey R, Cohen M, et al. Long-term tolerability of ticagrelor for the secondary prevention of major adverse cardiovascular events: a secondary analysis of the PEGASUS-TIMI 54 Trial. JAMA Cardiol. 2016;1(4):425-32.

48. Cornara S, Crimi G, Somaschini A, Cattaneo M, Angiolillo DJ, Palmerini T, et al. Systemic inflammatory status is associated with increased platelet reactivity in the early period after acute coronary syndromes. Platelets. 2018;29(5):528-30. 


\begin{abstract}
Introduction: In patients with acute coronary syndromes, ticagrelor is associated with reduced cardiovascular events, but may also lead to some increased risk of bleeding compared with clopidogrel. In addition, low platelet hyperreactivity under treatment with P2Y12 receptor inhibitors is one of the factors associated with increased bleeding risk. Purpose: To measure the prevalence of low platelet hyperreactivity in patients with acute myocardial infarction treated with ticagrelor. Methods: We included in our study individuals with acute myocardial infarction who were taking ticagrelor $(n=50,84 \%$ men, aged $59.3 \pm 12.7$ ) between March 2016 and January 2018. Blood samples were collected 1 hour before (trough) and 2 hours after (peak) maintenance dose (90mg) of ticagrelor. Platelet reactivity was measured by the Multiplate ${ }^{\circledR}$ and PFA-100 ${ }^{\circledR}$ methods with the Innovance ${ }^{\circledR}$ PFA-P2Y and Col/ADP cartridges. Patients with reactivity values $<19$ AUC for Multiplate ${ }^{\circledR}$ or occlusion time $>299$ seconds for $P F A^{\circledR} P 2 Y$ or $>116$ seconds for PFA ${ }^{\circledR} \mathrm{Col} / \mathrm{ADP}$ were considered hyperreactivity. Multiple logistic regression, adjusted for clinical and laboratory variables, was performed to identify factors associated with low platelet reactivity at the peak of action of ticagrelor. A p value of $<0.05$ was considered statistically significant. Results: The mean platelet reactivity at ticagrelor peak was $14 \pm 6$ AUC for Multiplate ${ }^{\circledR}, 277 \pm 60$ seconds for PFA ${ }^{\circledR} P 2 Y$ and $166 \pm 100$ seconds for $P F A^{\circledR} \mathrm{Col} / \mathrm{ADP}$. For each method, the comparison of trough to peak measurements showed no differences. The prevalence of low platelet reactivity at peak drug action was similar when measured by Multiplate ${ }^{\circledR}$ and PFA ${ }^{\circledR} \mathrm{P} 2 \mathrm{Y}$, but lower when measured by PFA ${ }^{\circledR}$ Col/ADP $(74 \%, 86 \%$, 48\%, respectively; $p<0.001)$. Conclusion: Patients with AMI treated with ticagrelor had a high prevalence of low platelet reactivity. The low platelet reactivity was more prevalent when measured by Multiplate ${ }^{\circledR}$ and PFA ${ }^{\circledR}$ P2Y compared with PFA ${ }^{\circledR}$ Col/ADP. Platelet inhibition was similar at the peak and trough analysis of the drug. Further studies are needed to assess whether lower doses of ticagrelor could attenuate the low platelet hyperreactivity, and reduce the bleeding risk of patients with acute myocardial infarction.
\end{abstract}

Keywords: Myocardial infarction; Ticagrelor; Bleeding; Platelet reactivity 